\title{
Updated guideline on the management of common bile duct stones (CBDS)
}

\author{
Earl Williams, ${ }^{1}$ Ian Beckingham, ${ }^{2}$ Ghassan El Sayed, ${ }^{1}$ Kurinchi Gurusamy, ${ }^{3}$ \\ Richard Sturgess, ${ }^{4}$ George Webster, ${ }_{1}^{5}$ Tudor Young ${ }^{6}$
}

'Bournemouth Digestive Diseases Centre, Royal Bournemouth and Christchurch NHS Hospital Trust,

Bournemouth, UK ${ }^{2}$ HPB Service, Nottingham University Hospitals NHS Trust, Nottingham, UK

${ }^{3}$ Department of Surgery, University College London Medical School, London, UK

${ }^{4}$ Aintree Digestive Diseases Unit, Aintree University Hospital Liverpool, Liverpool, UK ${ }^{5}$ Department of

Hepatopancreatobiliary Medicine, University College Hospital, London, UK ${ }^{6}$ Department of Radiology, The Princess of Wales Hospital, Bridgend, UK

Correspondence to Dr Earl Williams, Digestive Diseases Centre, Royal Bournemouth Hospital, Castle Lane East, Bournemouth BH7 7DW, UK; earl.williams@rbch. nhs.uk

Received 25 May 2016 Revised 8 December 2016 Accepted 15 December 2016 Published Online First 25 January 2017

\section{ABSTRACT}

Common bile duct stones (CBDS) are estimated to be present in $10-20 \%$ of individuals with symptomatic gallstones. They can result in a number of health problems, including pain, jaundice, infection and acute pancreatitis. A variety of imaging modalities can be employed to identify the condition, while management of confirmed cases of CBDS may involve endoscopic retrograde cholangiopancreatography, surgery and radiological methods of stone extraction. Clinicians are therefore confronted with a number of potentially valid options to diagnose and treat individuals with suspected CBDS. The British Society of Gastroenterology first published a guideline on the management of CBDS in 2008. Since then a number of developments in management have occurred along with further systematic reviews of the available evidence. The following recommendations reflect these changes and provide updated guidance to healthcare professionals who are involved in the care of adult patients with suspected or proven CBDS. It is not a protocol and the recommendations contained within should not replace individual clinical judgement.

\section{SUMMARY OF RECOMMENDATIONS}

Where recommendations from the 2008 guidelines ${ }^{1}$ are obsolete, they are omitted. Where recommendations are prefaced by '2008' there has been no new evidence found since the last guideline and no change in the recommendation; '2008, amended 2016' indicates that while no new evidence has been found since the last guideline there has been a change in wording that effects the meaning of the recommendation; '2016' indicates that new evidence has been found and no change in the recommendation is necessary; 'New 2016' indicates that new evidence has resulted in a new or amended recommendation.

\section{General principles in management of common bile duct stones \\ New 2016}

It is recommended that patients diagnosed with common bile duct stones (CBDS) are offered stone extraction if possible. Evidence of benefit is greatest for symptomatic patients. (Low-quality evidence; strong recommendation)

\section{Identifying individuals with CBDS}

New 2016

Trans-abdominal ultrasound scanning (USS) and liver function tests (LFTs) are recommended for patients with suspected CBDS. Normal results do not preclude further investigation if clinical suspicion remains high. (Low-quality evidence; strong recommendation)

New 2016

Magnetic resonance cholangiopancreatography (MRCP) and endoscopic ultrasound (EUS) are both recommended as highly accurate tests for identifying CBDS among patients with an intermediate probability of disease. MRCP predominates in this role, with choice between the two modalities determined by individual suitability, availability of the relevant test, local expertise and patient acceptability. (Moderate quality evidence; strong recommendation)

\section{New 2016}

It is suggested that patients with suspected CBDS who have not been previously investigated should undergo USS and LFTs. For patients with an intermediate probability of stones, MRCP or EUS is recommended as a next step unless the patient is proceeding directly to cholecystectomy supplemented by intraoperative cholangiography (IOC) or laparoscopic ultrasound (LUS). Endoscopic retrograde cholangiopancreatography (ERCP) should be reserved for patients in whom preceding assessment indicates a need for endoscopic therapy. (Lowquality evidence; weak recommendation)

\section{Endoscopic management of CBDS}

New 2016

It is suggested that the British Society of Gastroenterology (BSG) national standards framework for ERCP is implemented by service providers. (Very low-quality evidence; weak recommendation)

\section{New 2016}

For selected patients, tolerability and likelihood of therapeutic success is higher if ERCP is performed with propofol sedation or general anaesthesia. It is recommended that hospitals looking after patients with CBDS should have ready and prompt access to anaesthesia supported ERCP. This can be an on-site service or provided by another ERCP unit as part of a clinical network. (Low-quality evidence; strong recommendation)

\section{8}

It is suggested that patients should be managed in accordance with the BSG guidelines on antibiotic prophylaxis during endoscopy. (Very low-quality evidence; weak recommendation)

\section{New 2016}

To reduce the risk of post-ERCP pancreatitis (PEP) it is recommended that diclofenac or indomethacin 
(at a dose of $100 \mathrm{mg}$ ) should be administered rectally at the time of ERCP to all patients who do not have a contraindication to non-steroidal anti-inflammatory drugs (NSAIDs). (Moderate-quality evidence; strong recommendation)

\section{New 2016}

In patients with a high risk of PEP arising from repeated pancreatic duct cannulation, insertion of a pancreatic stent is suggested in addition to administration of rectal NSAID. (Moderatequality evidence; weak recommendation)

\section{8, amended 2016}

It is recommended that patients undergoing biliary sphincterotomy for ductal stones have a full blood count (FBC) and international normalised ratio or prothrombin time (INR/PT) performed prior to their ERCP. If deranged clotting or thrombocytopenia is identified, subsequent management should conform to locally agreed guidelines. (Low-quality evidence; strong recommendation)

\section{New 2016}

It is recommended that ERCP patients taking warfarin, antiplatelet treatment or a direct oral anticoagulant (DOAC) should be managed in accordance with the combined BSG and European Society of Gastrointestinal Endoscopy (ESGE) guidelines for patients undergoing endoscopy. (Low-quality evidence; strong recommendation)

2008, amended 2016

Competency in access papillotomy is suggested for all endoscopists who perform ERCP. Training and subsequent mentorship should facilitate this. (Very low-quality evidence; weak recommendation)

\section{New 2016}

As an adjunct to biliary sphincterotomy, endoscopic papillary balloon dilation (EPBD) is recommended as a technique to facilitate removal of large CBDS. (High-quality evidence; strong recommendation)

\section{New 2016}

EPBD without prior biliary sphincterotomy is associated with an increased risk of PEP but may be considered as an alternative to biliary sphincterotomy in selected patients, such as those with an uncorrected coagulopathy or difficult biliary access due to altered anatomy. If EPBD is performed without prior biliary sphincterotomy, use of an $8 \mathrm{~mm}$ diameter balloon is recommended. (Moderate-quality evidence; strong recommendation)

\section{New 2016}

It is recommended that cholangioscopy-guided electrohydraulic lithotripsy (EHL) or laser lithotripsy (LL) be considered when other endoscopic treatment options fail to achieve duct clearance. (Low-quality evidence; strong recommendation)

\section{Surgical management of CBDS}

New 2016

IOC or LUS can be used to detect CBDS in patients who are suitable for surgical exploration or postoperative ERCP. Although not considered mandatory for all patients undergoing cholecystectomy, IOC or LUS is suggested for those patients who have an intermediate to high pre-test probability of CBDS and who have not had the diagnosis confirmed preoperatively by USS, MRCP or EUS. (Low-quality evidence; weak recommendation)

\section{6}

It is recommended that, in patients undergoing laparoscopic cholecystectomy, transcystic or transductal laparoscopic bile duct exploration (LBDE) is an appropriate technique for CBDS removal. There is no evidence of a difference in efficacy, mortality or morbidity when LBDE is compared with perioperative ERCP, although LBDE is associated with a shorter hospital stay. It is recommended that the two approaches are considered equally valid treatment options. (High-quality evidence; strong recommendation)

\section{New 2016}

It is suggested that training of surgeons in LBDE is to be encouraged in order to decrease the number of interventions required to manage CBDS. (Low-quality evidence; weak recommendation)

\section{Management of 'difficult' ductal stones \\ New 2016}

Laparoscopic duct exploration and ERCP (supplemented by EPBD with prior sphincterotomy, mechanical lithotripsy or cholangioscopy where necessary) are highly successful in removing CBDS. It is recommended that percutaneous radiological stone extraction and open duct exploration should be reserved for the small number of patients in whom these techniques fail or are not possible. (Low-quality evidence; strong recommendation)

\section{New 2016}

When endoscopic cannulation of the bile duct is not possible with standard techniques including access papillotomy, it is recommended that percutaneous or EUS-guided procedures can be considered as a means of facilitating subsequent ERCP. (Lowquality evidence; strong recommendation)

\section{6}

It is important that endoscopists ensure adequate biliary drainage is achieved in patients with CBDS that have not been extracted. The short-term use of a biliary stent followed by further endoscopy or surgery is recommended. (Moderatequality evidence; strong recommendation)

\section{6}

The use of a biliary stent as sole treatment for CBDS should be restricted to a selected group of patients with limited life expectancy and/or prohibitive surgical risk. (Moderate-quality evidence; strong recommendation)

\section{Management of CBDS in specific clinical setting New 2016}

Cholecystectomy is recommended for all patients with CBDS and gall bladder stones unless there are specific reasons for considering surgery inappropriate. (High-quality evidence; strong recommendation)

Where operative risk is deemed prohibitive, biliary sphincterotomy and endoscopic duct clearance alone is suggested as an acceptable alternative. (Low-quality evidence; weak recommendation)

2008

Biliary sphincterotomy and endoscopic stone extraction is recommended as the primary form of treatment for patients with CBDS post cholecystectomy. (Low-quality evidence; strong recommendation) 
New 2016

Patients with acute cholangitis who fail to respond to antibiotic therapy or who have signs of septic shock require urgent biliary decompression. Endoscopic CBDS extraction and/or biliary stenting are recommended in this setting. If ERCP is not possible, percutaneous radiological drainage can be considered as an alternative. (Moderate-quality evidence; strong recommendation)

\section{New 2016}

Patients with pancreatitis of suspected or proven biliary origin who have associated cholangitis or persistent biliary obstruction are recommended to undergo biliary sphincterotomy and endoscopic stone extraction within 72 hours of presentation. (High-quality evidence; strong recommendation)

\section{New 2016}

It is recommended that following gallstone pancreatitis early laparoscopic cholecystectomy should be offered to all patients on whom it is safe to operate as the most effective means to prevent recurrent episodes. (Moderate-quality evidence, strong recommendation)

\section{New 2016}

In cases of mild acute gallstone pancreatitis, it is advised that cholecystectomy should be performed within 2 weeks of presentation and preferably during the same admission. (Moderate-quality evidence; weak recommendation)

\section{New 2016}

It is recommended that patients with gallstone pancreatitis who do not require ERCP within 72 hours of presentation should be considered for elective ERCP and endoscopic sphincterotomy if there is evidence of retained CBDS on imaging or the patient is unsuitable for definitive treatment in the form of cholecystectomy. (Moderate-quality evidence; strong recommendation)

\section{New 2016}

ERCP for CBDS extraction can be successfully performed in patients with Billroth II anatomy. Where ERCP with a duodenoscope is difficult, use of a forward viewing endoscope is recommended. (Moderate-quality evidence; weak recommendation)

In cases where biliary sphincterotomy cannot be safely completed, a limited sphincterotomy supplemented by EPBD is suggested as an alternative. (Low-quality evidence; weak recommendation)

\section{New 2016}

Patients with Roux-en-Y gastric bypass (RYGB) and CBDS should be referred to centres that are able to offer the advanced endoscopic and surgical treatment options that are necessary for stone extraction. (Low-quality evidence; weak recommendation)

\section{MEMBERS OF GUIDELINE DEVELOPMENT GROUP AND ACKNOWLEDGEMENTS}

The guideline development group (GDG) comprised of the following members:

Earl Williams. Consultant hepatologist, Royal Bournemouth Hospital, representing BSG. Chair of GDG, Editor and lead for introductory and concluding sections; section on general principles in the management of CBDS and section on identification of individuals with CBDS.
Peggy and Hannah Anderson. Patient representatives, approached via British Liver Trust.

Ian Beckingham, Consultant HPB surgeon, Nottingham University Hospitals, representing Association of Upper Gastrointestinal Surgeons of Great Britain and Ireland (AUGIS) and Royal College of Surgeons. Lead for section on surgical management of CBDS.

Ghassan El Sayed. ERCP fellow, Royal Bournemouth Hospital. Representing GI trainees. Responsible for literature search.

Kurinchi Gurusamy, Reader in Surgery, University College London and member of European Association for the Study of the Liver guidelines panel for management of gallstones. Co-author of sections on development process for guideline; identifying individuals with CBDS and surgical management of CBDS.

Richard Sturgess, Consultant hepatologist, Aintree Hospital Liverpool, representing BSG. Lead for sections on management of "difficult" ductal stones and management of CBDS in specific clinical settings.

George Webster. Consultant gastroenterologist, University College Hospital, representing BSG. Lead for section on endoscopic management of CBDS.

Tudor Young, Consultant GI Radiologist, The Princess of Wales Hospital, Bridgend. Representing Royal College of Radiologists and British Society of Gastrointestinal and Abdominal Radiology. Co-author of section on identifying individuals with CBDS.

The GDG would like to acknowledge the following individuals and organisations:

Jonathon Green, Rowan Parks, Derrick Martin and Martin Lombard; co-authors of the 2008 BSG guidelines on management of CBDS.

Andrew Langford, Chief Executive, British Liver Trust.

Ashley Guthrie, President of the British Society of Gastrointestinal and Abdominal Radiology.

\section{DEVELOPMENT PROCESS FOR CURRENT GUIDELINE}

The updated guideline was commissioned by the BSG in 2014. The purpose of the updated guideline was to provide guidance to healthcare professionals who are involved in the care of adult patients with suspected or proven CBDS. The chair convened a GDG, consisting of clinicians and patients with experience in this area. Members of the GDG were selected to ensure relevant professional bodies and specialities were represented. Authors were required to declare any interests. The AGREE II instrument ${ }^{2}$ was used as a framework to assist in guideline development. Key questions were derived from the content of the previous guideline and can be summarised as

1. When should investigation and treatment for CBDS be considered? (General principles in the management of CBDS)

2. What is the best way of identifying patients with CBDS? (Identifying individuals with CBDS)

3. When undertaking ERCP for CBDS, what can be done to improve success rates and minimise risk? (Endoscopic management of CBDS)

4. What is the role of surgery in managing CBDS? (Surgical management of CBDS)

5. In patients with CBDS that are difficult to treat, what are the management options? (Management of "difficult" ductal stones)

6. How should CBDS be managed in the most commonly encountered clinical settings? (Management of CBDS in specific clinical settings) 
A literature search was performed using PubMed and Medline. The search terms employed were common bile duct stones, gallstones, choledocholithiasis, laparoscopic cholecystectomy, ERCP, sphincteroplasty and cholangioscopy. The search was restricted to English-language articles published 6 months before the last BSG guideline or later (ie, June 2007 onwards).

Articles were selected by title and their relevance confirmed by review of the corresponding abstract. Systematic reviews and full-length reports of prospective design were sought. Retrospective analyses and case reports were also retrieved if the topic had not been addressed by prospective study. Guidelines published by national and international bodies were automatically included for review. Data published in abstract form only were considered if full-length papers addressing the same issue were lacking.

The GDG corresponded with one another to identify the principal clinical developments since publication of the 2008 guideline. The topics that would need to be addressed in order to answer the key questions were agreed at this point and each section of the guideline was assigned a lead author. Upon completion of the literature search, section leads drafted preliminary recommendations linked to a referenced narrative. As part of this, they were asked to search the reference lists of retrieved papers for missing articles and were also free to suggest additional references for consideration. The GDG met at University College Hospital London on 13 December 2014. The output from each section lead was reviewed and each recommendation contained within the 2008 guidelines was considered and judged as being still valid, in need of revision, obsolete or no longer valid. A new set of recommendations were generated at this meeting. Evidence was graded for each recommendation by discussion and consensus among the GDG members, based on the group's confidence in the effect of an intervention and whether further research was likely to alter confidence in the estimate (table 1). The GDG took account of the principles of the GRADE working group ${ }^{3}$ and considered risk of bias in the included studies, inconsistency, indirectness, imprecision and publication bias. However, given the large number of interventions examined the group did not attempt to produce outcome

Table 1 Grading of evidence ${ }^{4}$

\begin{tabular}{|c|c|c|}
\hline Rank & Explanation & Examples \\
\hline High & $\begin{array}{l}\text { Further research is very unlikely } \\
\text { to change our confidence in } \\
\text { the estimate of effect }\end{array}$ & $\begin{array}{l}\text { Randomised trials without serious } \\
\text { limitations } \\
\text { Well-performed observational } \\
\text { studies with very large effects (or } \\
\text { other qualifying factors) }\end{array}$ \\
\hline Moderate & $\begin{array}{l}\text { Further research is likely to } \\
\text { have an important impact on } \\
\text { our confidence in the estimate } \\
\text { of effect and may change the } \\
\text { estimate }\end{array}$ & $\begin{array}{l}\text { Randomised trials with serious } \\
\text { limitations } \\
\text { Well-performed observational } \\
\text { studies yielding large effects }\end{array}$ \\
\hline Low & $\begin{array}{l}\text { Further research is very likely to } \\
\text { have an important impact on } \\
\text { our confidence in the estimate } \\
\text { of effect and is likely to change } \\
\text { the estimate }\end{array}$ & $\begin{array}{l}\text { Randomised trials with very } \\
\text { serious limitations } \\
\text { Observational studies without } \\
\text { special strengths or important } \\
\text { limitations }\end{array}$ \\
\hline Very low & $\begin{array}{l}\text { Any estimate of effect is very } \\
\text { uncertain }\end{array}$ & $\begin{array}{l}\text { Randomised trials with very } \\
\text { serious limitations and } \\
\text { inconsistent results Observational } \\
\text { studies with serious limitations } \\
\text { Unsystematic clinical observations } \\
\text { (eg, case series or case reports) }\end{array}$ \\
\hline
\end{tabular}

Table 2 Grading of recommendations ${ }^{5}$

\begin{tabular}{|c|c|c|}
\hline & Strong recommendation & Weak recommendation \\
\hline Patients & $\begin{array}{l}\text { Most people in your situation } \\
\text { would want the recommended } \\
\text { course of action and only a } \\
\text { small proportion would not }\end{array}$ & $\begin{array}{l}\text { The majority of people in your } \\
\text { situation would want the } \\
\text { recommended course of action, } \\
\text { but many would not }\end{array}$ \\
\hline Clinicians & $\begin{array}{l}\text { Most patients should receive } \\
\text { the recommended course of } \\
\text { action }\end{array}$ & $\begin{array}{l}\text { Recognise that different choices } \\
\text { will be appropriate for different } \\
\text { patients and that you must } \\
\text { make greater effort to help } \\
\text { each patient to arrive at a } \\
\text { management decision } \\
\text { consistent with his or her } \\
\text { values and preferences; } \\
\text { decision aids and shared } \\
\text { decision making are particularly } \\
\text { useful }\end{array}$ \\
\hline Policymakers & $\begin{array}{l}\text { The recommendation can be } \\
\text { adopted as a policy in most } \\
\text { situations }\end{array}$ & $\begin{array}{l}\text { Policymaking will require } \\
\text { substantial debate and } \\
\text { involvement of many } \\
\text { stakeholders }\end{array}$ \\
\hline
\end{tabular}

tables with pooled estimates of effect. Recommendations were graded as either strong or weak (table 2).

The revised output from the group was reviewed by the BSG Endoscopy Committee on 13 May 2015. A draft document and was then forwarded to the Royal College of Surgeons, Royal College of Radiologists, AUGIS and the British Liver Trust. Comments from the professional and patient groups were received and considered by the GDG at a meeting held on the 27 September 2015. In a number of areas, it was recognised that while evidence was weak there was clear consensus among members of the GDG regarding the optimal clinical approach, and in this situation it was agreed by the contributors to make a strong recommendation. In keeping with BSG policy, the guideline was then reviewed by the Society's clinical services and standards committee, prior to submission for publication.

Additional references were incorporated into the guideline following anonymised international peer review and the finalised recommendations were ratified by the GDG.

\section{GENERAL PRINCIPLES IN THE MANAGEMENT OF CBDS New 2016}

It is recommended that patients diagnosed with CBDS are offered stone extraction if possible. Evidence of benefit is greatest for symptomatic patients. (Low-quality evidence; strong recommendation)

Primary ductal stones form de novo within the intrahepatic and extrahepatic ducts. They are most prevalent in Asian populations and give rise to the distinct clinical entity of recurrent pyogenic cholangitis. ${ }^{167}$ Secondary CBDS originate in the gall bladder and migrate into the bile duct via the cystic duct. They account for the majority of CBDS that occur in European patients. The following guideline focuses on the diagnosis and management of secondary CBDS.

Data suggest the prevalence of CBDS in patients with symptomatic gallstones lies between $10 \%$ and $20 \%,{ }^{8-13}$ although it should be noted that among patients where there is no clinical suspicion of ductal stones prior to surgery the incidence is significantly lower and is typically reported to be $<5 \%$. $^{14-20}$

Two to four per cent of individuals with stones within the gall bladder will develop symptoms over the course of a year. ${ }^{21} 22$ In 
comparison to gall bladder stones, the natural history of CBDS is less well understood. Complications of CBDS are potentially life threatening and include pain, partial or complete biliary obstruction leading to obstructive jaundice, cholangitis, hepatic abscesses, pancreatitis and secondary biliary cirrhosis. Such problems can occur without warning, ${ }^{23}$ but not all patients will experience difficulties secondary to CBDS. Studies confirm that a number of patients will spontaneously pass ductal stones into their duodenum before or after laparoscopic cholecystectomy. ${ }^{1424} 25$ That small unsuspected stones can have a benign natural history is also supported by trials of selective IOC, where the incidence of CBDS-related complications in patients who do not undergo cholangiography is reported to be low. ${ }^{17-20} 26$ This contrasts with a recent national cohort study that examined the outcomes of patients with proven CBDS at the time of cholecystectomy. In the GallRiks study, ${ }^{27} 34200$ patients underwent an IOC and $3969(11.6 \%)$ were found to have one or more CBDS. Of the 3828 patients for whom there were adequate follow-up data, $594(15.5 \%)$ received conservative treatment of their CBDS, while those remaining were recommended a treatment strategy that involved CBDS removal. Over a follow-up period that varied from 0 to 4 years $25.3 \%$ of patients in whom CBDS were left in situ experienced an unfavourable outcome (which was defined as pancreatitis, cholangitis, obstruction of the bile duct within 30 days of surgery or subsequent symptoms in association with proven CBDS on investigation with ERCP). Only $12.7 \%$ of patients for whom some form of stone extraction was scheduled experienced an unfavourable outcome (OR 0.44, 95\% CI 0.35 to 0.55 ). The benefits of active treatment persisted for patients with CBDS $<4 \mathrm{~mm}$ in diameter, where risk of unfavourable outcome with planned stone extraction was $8.9 \%$ versus $15.9 \%$ for patients treated conservatively (OR 0.52 , 95\% CI 0.34 to 0.79 ).

Therefore, in keeping with recent National Institute for Health and Care Excellence (NICE) guidelines, ${ }^{28}$ patients with CBDS should be offered stone extraction, assuming that they are fit enough to undergo treatment. It should be noted that there are no controlled studies examining the natural history of CBDS that are found incidentally in asymptomatic patients being investigated for other medical problems. Patients should be made aware that advice to undergo stone extraction in this setting is based on evidence from symptomatic patients and expert opinion.

\section{IDENTIFYING INDIVIDUALS WITH CBDS Introduction}

Clinical presentations that warrant investigation for CBDS include epigastric or right upper quadrant pain, ${ }^{29}$ especially if associated with jaundice ${ }^{30}$ and/or fever. ${ }^{31}$ CBDS should also be considered in patient with acute pancreatitis, where gallstones migrating to the CBD are estimated to be a causal factor in up to $50 \%$ of cases. ${ }^{32} 33$ A minority of patients do not present with classical symptoms. As a consequence, further tests are sometimes needed in patients with atypical abdominal symptoms that persist despite alternative forms of management. ${ }^{28}$

The following section examines the performance of the various tests available to the clinician and suggests an algorithm for investigation of patients with suspected CBDS.

\section{Role of trans-abdominal ultrasound and liver function tests New 2016}

Trans-abdominal USS and LFTs are recommended for patients with suspected CBDS. Normal results do not preclude further investigation if clinical suspicion remains high. (Low-quality evidence; strong recommendation)
USS and LFTs are cheap, widely available and safe. They are therefore potentially useful tests for patients who have not undergone previous assessment for possible CBDS. In recent years, a number of studies have examined the performance of one or other investigation. Measuring diagnostic accuracy is difficult as many such studies are subject to bias. ${ }^{34}$ In addition, the reference standards for patients identified as being at high risk of having ductal stones (ie, endoscopic or surgical exploration) are rarely employed in patients thought to be at low risk of the condition. This makes it difficult to accurately establish the incidence of false negative results. This is important if a normal test means the diagnosis of CBDS is discounted. However, a recent Cochrane analysis $^{34}$ has been performed based on studies that incorporated at least six months of clinical follow-up for patients who did not undergo endoscopic or surgical exploration. ${ }^{35-39}$ Assuming a pre-test probability of 0.095 (9.5\%), this analysis reported that 45 out of 100 patients with a positive USS, variously defined in studies as the presence of echogenic material in the CBD or CBD dilatation, will have CBDS, rising to 85 out of 100 if pre-test probability is $0.408(40.8 \%)$. Conversely in patients with a negative USS, 3 out of 100 patients with a pre-test probability of 0.095 (9.5\%) will have CBDS versus 17 out of 100 patients with a pre-test probability of $0.408(40.8 \%)$. Analogous results for LFTs were dependent on the parameter and cut-off points used, but, if pre-test probability was $0.095(9.5 \%), 32$ out of 100 patients with an alkaline phosphatase of $>125 \mathrm{IU} / \mathrm{L}$ would have CBDS versus 2 out of 100 patients with an alkaline phosphatase that was $<125 \mathrm{IU} / \mathrm{L}$ (noting the average alkaline phosphatase level in an adult population is between 50 and $170 \mathrm{IU} / \mathrm{L}$ ). The performance of both USS and LFTs according to the pre-test probability of CBDS is summarised in table 3 .

These results are helpful in formulating guidance, although it is important to note that clinicians routinely use both LFTs and USS together having first taken into account the pre-test probability of stones, based on clinical history. This strategy is likely to be more effective than the isolated use of any one parameter. $^{40-44}$

When there is a persistent suspicion of CBDS and results of LFTs and USS are non-diagnostic, further investigation may be necessary as both USS and LFTs can be normal in people with CBDS.

\section{Magnetic resonance cholangiopancreatography and endoscopic ultrasound \\ New 2016}

MRCP and EUS are both recommended as highly accurate tests for identifying CBDS among patients with an intermediate probability of disease. MRCP predominates in this role, with choice between the two modalities determined by individual suitability, availability of the relevant test, local expertise and patient acceptability. (Moderate-quality evidence; strong recommendation)

MRCP is produced by a heavily $\mathrm{T} 2$-weighted scan sequence that displays fluid, such as bile, as a high-intensity bright signal on the resulting images. Solid material such as CBDS will appear as well-defined, dark-filling defects within the CBD. An echo-endoscope when positioned in the duodenal bulb uses high-frequency sound waves to image the bile duct. When using EUS, CBDS appear as hyperechoic foci, with characteristic acoustic shadowing.

Studies that examine the performance of MRCP and/or EUS are heterogeneous with regard to patient selection and reference standards used. The potential for bias is also a concern (when, for example, researchers are aware of index test results when 
Table 3 Performance of ultrasound scanning and liver function tests according to pre-test probability ${ }^{34}$

\begin{tabular}{|c|c|c|c|c|c|}
\hline Test (cut-off) & $\begin{array}{l}\text { Summary sensitivity } \\
(95 \% \mathrm{Cl})\end{array}$ & $\begin{array}{l}\text { Summary specificity } \\
(95 \% \mathrm{Cl})\end{array}$ & Pre-test probability & $\begin{array}{l}\text { Positive post-test } \\
\text { probability } \\
(95 \% \mathrm{Cl})\end{array}$ & $\begin{array}{l}\text { Negative post-test } \\
\text { probability } \\
(95 \% \mathrm{Cl})\end{array}$ \\
\hline Ultrasound & $0.73(0.44$ to 0.90$)$ & 0.91 (0.84 to 0.95 ) & $\begin{array}{l}0.095 \\
0.408 \\
0.658\end{array}$ & $\begin{array}{l}0.45(0.31 \text { to } 0.60) \\
0.85(0.75 \text { to } 0.91) \\
0.94(0.89 \text { to } 0.97)\end{array}$ & $\begin{array}{l}0.03(0.01 \text { to } 0.07) \\
0.17(0.08 \text { to } 0.33) \\
0.37(0.20 \text { to } 0.58)\end{array}$ \\
\hline Bilirubin $(>22.23 \mu \mathrm{mol} / \mathrm{L})$ & 0.84 (0.64 to 0.94 ) & 0.91 (0.86 to 0.94 ) & 0.095 & $0.49(0.38$ to 0.59$)$ & 0.02 (0.01 to 0.04$)$ \\
\hline Bilirubin (>twice the normal limit) & $0.42(0.22$ to 0.63$)$ & $0.97(0.95$ to 0.99$)$ & 0.095 & $0.63(0.41$ to 0.81$)$ & $0.06(0.04$ to 0.08$)$ \\
\hline Alkaline phosphatase (>125 IU/L) & 0.92 (0.74 to 0.99 ) & 0.79 (0.74 to 0.84$)$ & 0.095 & 0.32 (0.26 to 0.38$)$ & 0.01 (0.00 to 0.04 ) \\
\hline Alkaline phosphatase (>twice the normal limit) & $0.38(0.19$ to 0.59$)$ & 0.97 (0.95 to 0.99$)$ & 0.095 & $0.61(0.38$ to 0.80$)$ & 0.06 (0.05 to 0.08$)$ \\
\hline
\end{tabular}

interpreting the reference standard). Nonetheless, when analysis is restricted to published data that incorporate at least six months clinical follow-up for patients who do not undergo duct exploration, ${ }^{45-62}$ it is possible to demonstrate that both MRCP and EUS perform well. Specifically at a median pre-test probability for CBDS of 0.41 (41\%), Cochrane systematic review data $^{63}$ indicate that the summary sensitivity of EUS is $0.95 \mathrm{com}-$ pared with 0.93 for MRCP, while summary specificity is 0.97 for EUS compared with 0.96 for MRCP. These results are consistent with other published reviews. ${ }^{64} 65$ It is important to note that the performance quoted does not apply to patients at low pre-test probability of stones (where the incidence of false positives can be expected to be higher) or patients with high pre-test probability of stones (where the clinician needs to be mindful of false negative results).

In keeping with the above observations, studies that subject the same group of patients to both EUS and MRCP 515366 do not demonstrate clear superiority of one test over the other in relation to diagnosis of CBDS.

Factors that favour EUS over MRCP are that it can be performed in the presence of intracranial metallic clips, cardiac pace makers, mechanical heart valves, claustrophobia and morbid obesity. Factors that favour MRCP over EUS include its wide availability, minimally invasive nature, ability to image the intrahepatic ducts, cost effectiveness ${ }^{67}$ and suitability for patients with altered gastric or duodenal anatomy. In addition, all images can be captured allowing for review by other clinicians at a later date. For these reasons, current NICE guidelines $^{28}$ suggest that in most cases MRCP represents the safest and most acceptable test for patients, while acknowledging that appropriately skilled clinicians may choose to use EUS instead and a minority of patients may need both investigations to ensure an accurate diagnosis.

\section{CT}

CT plays an important role in the identification and staging of malignant biliary obstruction but is not routinely used for the express purpose of detecting CBDS. Formal CT cholangiography, using excreted biliary contrast, is a useful and accurate diagnostic tool ${ }^{68-71}$ for ductal stones but the required contrast agent has not been available in the UK since 2009. Recent studies using data from modern multislice scanners suggest that standard contrasted CT scanning can also achieve reasonable sensitivity (69-87\%) and specificity (68-96\%) for detecting CBDS, ${ }^{72-75}$ although diagnostic accuracy decreases considerably when calculi are small or of similar density to bile. In addition, $\mathrm{CT}$ exposes patients to the potential harm of ionising radiation and contrast injection.

In current clinical practice, CT is widely used to investigate patients who present with pain or other abdominal symptoms and it is inevitable that a proportion of CBDS will be diagnosed this way. Sensitivity is best when radiologists look specifically for the presence of CBDS. ${ }^{72}$ The available evidence favours EUS or MRCP as the investigations of choice for CBDS, but CT is an important and appropriate diagnostic test for patients in whom features of CBDS and malignancy coexist.

\section{Suggested algorithm for investigation of suspected CBDS New 2016}

It is suggested that patients with suspected CBDS who have not been previously investigated should undergo USS and LFTs. For patients with an intermediate probability of stones, MRCP or EUS is recommended as a next step unless the patient is proceeding directly to cholecystectomy supplemented by IOC or LUS. ERCP should be reserved for patients in whom preceding assessment indicates a need for endoscopic therapy. (Low-quality evidence; weak recommendation)

The probability of CBDS may be established on history, LFTs and USS. For example, the American Society of Gastrointestinal Endoscopy (ASGE) indicates that in patients with symptomatic gall bladder stones there is a high likelihood of CBDS if a calculus is visible in the CBD on USS, there are features of cholangitis or the patient presents with a combination of CBD dilatation on USS and jaundice. ${ }^{76}$ Further investigation prior to scheduling endoscopic or surgical duct clearance is not mandated in this setting, although the need for CT to exclude pancreatobiliary malignancy should always be considered according to the clinical scenario. For other patients, the likelihood will either be considered low (on the basis of normal LFTs and USS in the absence of a preceding clinical predictor such as cholangitis or gallstone pancreatitis) or intermediate. Among the latter group, a common scenario is pain with abnormal LFTs in the absence of duct dilatation on USS or vice versa. Further investigation of patients with a low or intermediate likelihood of CBDS is recommended prior to undertaking endoscopic or surgical bile duct clearance. A suggested pathway for investigation of suspected CBDS is described in figure 1.

\section{ENDOSCOPIC MANAGEMENT OF CBDS Introduction \\ New 2016}

It is suggested that the BSG national standards framework for ERCP is implemented by service providers. (Very low-quality evidence; weak recommendation)

ERCP is a minimally invasive technique that is an effective treatment for CBDS. ${ }^{77}$ High rates of duct clearance are possible, although the potential for serious adverse events is also recognised. ${ }^{77-79}$ In a large observational study conducted in England in 2004, >5\% of patients undergoing ERCP experienced some 


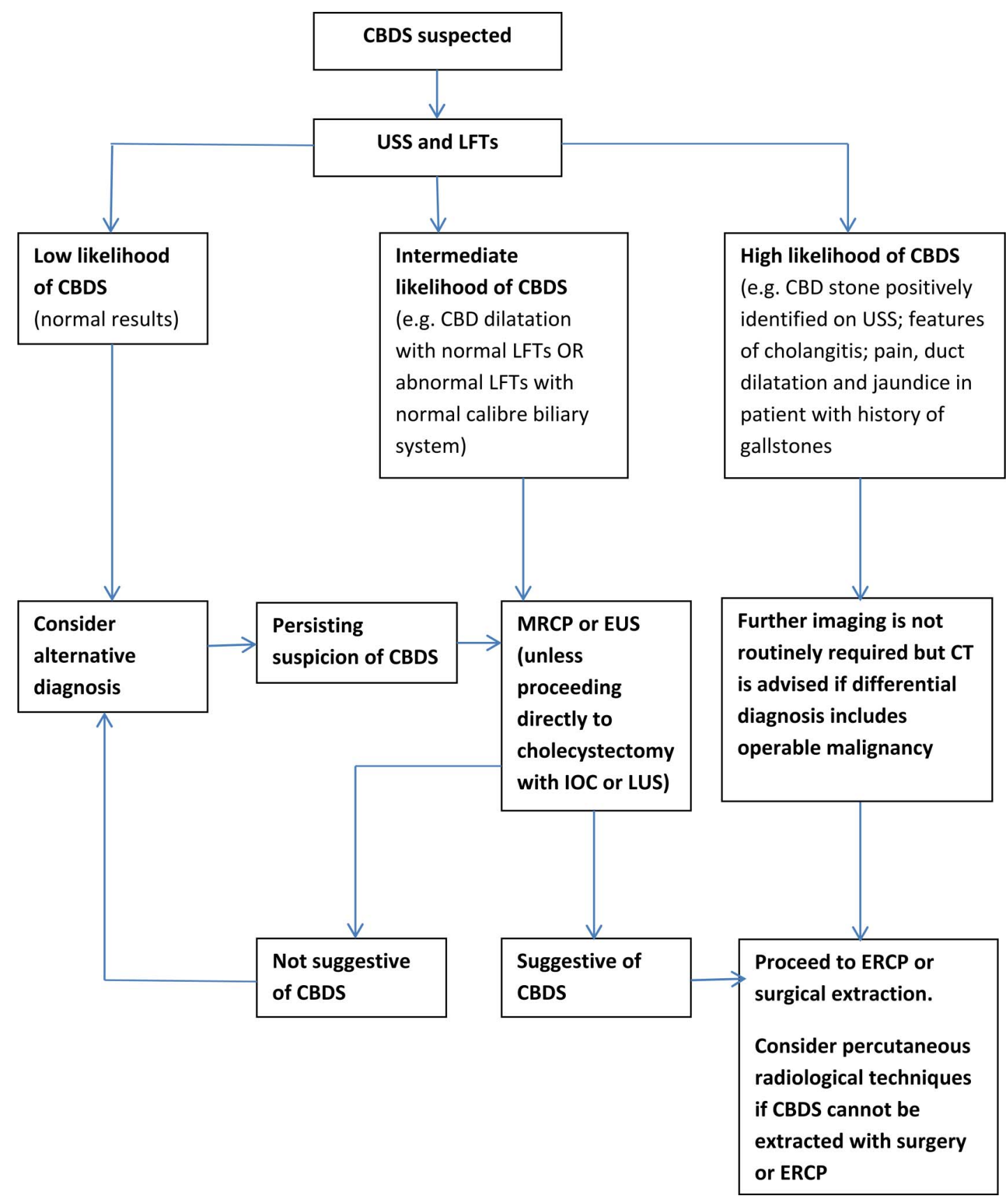

Figure 1 Investigation of suspected common bile duct stone (CBDS). ERCP, endoscopic retrograde cholangiopancreatography; EUS, endoscopic ultrasound; IOC, intraoperative cholangiography; LFT, liver function test; LUS, laparoscopic ultrasound; MRCP, magnetic resonance cholangiopancreatography; USS, ultrasound scanning.

form of complication, including acute pancreatitis, bleeding, perforation and biliary sepsis. ${ }^{80}$ As such, it is essential that the UK offers high-quality training and that clinicians are able to maintain their skills in appropriately resourced facilities. Previous BSG guidelines made a number of recommendations in relation to this. These have recently been updated in the form of a national standards framework for ERCP, ${ }^{81}$ published in 2014. This describes the minimum standards that service providers should adhere to and also recommends a set of achievable standards that service providers should work towards implementing.

In addition, several important developments in ERCP practice have occurred in the last 10 years, which have the potential to improve success rates and minimise risk. These are described below.

\section{Anaesthesia-supported ERCP}

New 2016

For selected patients, tolerability and likelihood of therapeutic success is higher if ERCP is performed with propofol sedation or general anaesthesia. It is recommended that hospitals looking after patients with CBDS should have ready and prompt access to anaesthesia supported ERCP. This can be an on-site service or provided by another ERCP unit as part of a clinical network. (Low-quality evidence; strong recommendation)

The great majority of ERCPs in the UK are performed under conscious sedation (ie, intravenous benzodiazepine and opiate) and are generally well tolerated. However 14\% of ERCPs performed under conscious sedation are reported to be poorly tolerated, ${ }^{82}$ and this is an important cause of unsuccessful 
therapeutic ERCP. ${ }^{83}$ In the setting of CBDS, this outcome almost always necessitates further procedures and delays in achieving clinical resolution. Anecdotally it may be an important cause of distress for individuals undergoing the procedure as was highlighted by the GDG's patient representatives. Failure to complete the procedure may also present a clinical risk. The duration and complexity of ERCP often necessitates doses of benzodiazepine that are higher than routine diagnostic endoscopy. The national BSG audit of ERCP in 2004 showed that $33 \%$ of patients received $>5.5 \mathrm{mg}$ of midazolam and approximately $8 \%$ of patients required the administration of reversal agents (flumazenil or naloxone). ${ }^{80}$ Although high-quality evidence on the optimal form of sedation for ERCP is lacking, ${ }^{84}$ most ERCP services in Western Europe and North America now use enhanced sedation (eg, with propofol) or general anaesthesia as standard. In 2011, the BSG issued guidance in conjunction with the Royal College of Anaesthetists regarding the use of propofol sedation without the need for tracheal intubation in patients undergoing ERCP and other complex endoscopic procedures. ${ }^{85}$ These guidelines highlighted the minimum requirements for all endoscopic units wanting to deliver this service. In contrast to other healthcare systems, there is a lack of support in the UK for propofol-anaesthesia at endoscopy to be administered by non-anaesthetists. In patients with CBDS who require long and complex endoscopic procedures (eg, cholangioscopy-assisted EHL), a lack of enhanced sedation/general anaesthesia has been correlated with lack of therapeutic success. ${ }^{86}$ Propofol-assisted ERCP in UK practice has recently been shown to be safe and to be associated with high rates of ERCP success and patient satisfaction. $^{87}$

In summary, clinician and patient opinion is in favour of wider availability of anaesthetist-assisted ERCP in the UK. The demand for propofol-assisted ERCP is likely to increase and should be specifically considered for complex cases of CBDS (eg, intrahepatic ductal stones and cholangioscopy-assisted lithotripsy). General anaesthesia with endotracheal intubation is an alternative but is generally reserved for patients with anaesthetic issues independent of those related to ERCP per se (eg, morbid obesity, airway/ventilation problems).

\section{Antibiotic use during endoscopic stone extraction 2008}

It is suggested that patients should be managed in accordance with the BSG guidelines on antibiotic prophylaxis during endoscopy. (Very low-quality evidence; weak recommendation)

No changes have been made to the recommendation on antibiotic use published as part of the 2008 guidelines on CBDS. ${ }^{1}$ In the absence of specific risk factors for sepsis such as sclerosing cholangitis, communicating pancreatic cysts, hilar strictures, liver transplantation, cholangioscopy or a failed attempt to drain an opacified bile duct, it is suggested that prophylactic antibiotics can be safely avoided.

\section{Prophylaxis of PEP \\ New 2016}

To reduce the risk of PEP, it is recommended that diclofenac or indomethacin (at a dose of $100 \mathrm{mg}$ ) should be administered rectally at the time of ERCP to all patients who do not have a contraindication to NSAIDs. (Moderate-quality evidence; strong recommendation)

\section{New 2016}

In patients with a high risk of PEP arising from repeated pancreatic duct cannulation, insertion of a pancreatic stent is suggested in addition to administration of rectal NSAID. (Moderatequality evidence; weak recommendation)

Acute pancreatitis is a well-recognised complication of ERCP. The frequency of PEP varies considerably in the literature (from $<1 \%$ to $>20 \%$ ), with $2-5 \%$ commonly reported. ERCP for bile duct stones does not confer an inherent increased risk of PEP above the baseline rate described for all forms of therapeutic ERCP. However, the only way of definitively avoiding risk of PEP is by avoiding ERCP. This fact emphasises the necessity of reserving ERCP as a therapeutic procedure for patients with proven bile duct stones, with the diagnosis made through modalities carrying little or no risk of PEP (eg, USS, EUS or MRCP as described above).

In people who require ERCP, a number of prophylactic approaches may reduce the risks of PEP. The most important recent advance is in the use of prophylactic NSAIDs. High-quality randomised control trials (RCTs) have unequivocally demonstrated the benefit of rectal NSAIDs (100 mg indomethacin or diclofenac), ${ }^{88} 89$ and a recent ESGE practice guideline has recommended this in all patients undergoing ERCP, unless there is a contraindication. ${ }^{90}$ Short-term pancreatic duct stenting at ERCP reduces the risk of PEP in patients at increased risk of this complication by virtue of patient-specific factors (young age, female sex, suspected Sphincter of Oddi dysfunction) or procedure-specific factors (repeated pancreatic duct cannulation), ${ }^{91}$ but also in mixed-risk populations that include those undergoing ERCP for CBDS. ${ }^{92}$ Pancreatic duct cannulation or contrast-filling should be avoided at ERCP for CBDS wherever possible. If pancreatic duct cannulation repeatedly occurs (eg, > 1 pancreatic wire passage) while attempting to gain biliary access, insertion of a $5 \mathrm{~F}$ pancreatic stent can be considered. ${ }^{90} 93$ This may both facilitate biliary access and reduce the risk of PEP. Importantly, failed attempts at stent placement may dramatically increase the risk of PEP, and so endoscopists who perform ERCP require appropriate training in this technique. The optimum duration of placement is unknown but likely to be hours to days. As such, ERCP units should reassess patients after pancreatic stent insertion to confirm spontaneous migration. A plain abdominal X-ray is the simplest method for demonstrating this. Where spontaneous migration does not occur, endoscopic removal is recommended. ${ }^{90}$ With the universal use of rectal NSAIDs, the additive benefit of pancreatic stents in the prevention of PEP is uncertain. ${ }^{94}$

\section{Coagulopathy prior to sphincterotomy}

2008, amended 2016

It is recommended that patients undergoing biliary sphincterotomy for ductal stones have an FBC and INR/PT performed prior to their ERCP. If deranged clotting or thrombocytopenia is identified, subsequent management should conform to locally agreed guidelines. (Low-quality evidence; strong recommendation)

\section{New 2016}

It is recommended that ERCP patients taking warfarin, antiplatelet treatment or a DOAC should be managed in accordance with the combined BSG and ESGE guidelines for patients undergoing endoscopy. (Low-quality evidence; strong recommendation)

Abnormal clotting is a feature of biliary obstruction and parenchymal liver disease. Portal hypertension and severe sepsis can also result in thrombocytopenia. A recognised complication of biliary sphincterotomy is GI haemorrhage but the point at which clotting abnormalities become an absolute 
contraindication to sphincterotomy cannot be asserted from the available evidence. Nonetheless, attempts should be made to correct coagulopathy (including severe thrombocytopenia) before performing sphincterotomy, and if this is not possible initial therapy should involve a procedure with an inherently lower risk of bleeding such as endoscopic stenting. It is therefore recommended that patients undergoing biliary sphincterotomy for ductal stones should have an FBC and INR/PT performed prior to their ERCP. If deranged clotting is identified, subsequent management should conform to locally agreed guidelines.

For patients taking warfarin or antiplatelet treatment, the previous BSG guideline ${ }^{95}$ has been incorporated into a new BSG and ESGE guideline, ${ }^{96}$ which includes advice on patients prescribed DOACs. This class of drugs include factor 10a inhibitors (rivaroxaban, apixiban) and the thrombin inhibitor dabigatran. They benefit from fewer drug interactions than warfarin and have shorter half-lives. However, they cannot be readily reversed and INR cannot be used to assess bleeding risk. ${ }^{97-99}$ In the context of ERCP, management of antiplatelet and oral anticoagulant therapy will vary depending on the medication prescribed, the reason for its use and on whether a high-risk procedure (sphincterotomy) or low-risk procedure (stenting) is being considered. For patients taking warfarin, antiplatelet treatment or DOAC, it is recommended that clinicians follow the management algorithms presented in the combined BSG and ESGE guidelines. ${ }^{96}$ These guidelines advise that for endoscopic stenting alone warfarin is continued and DOACs omitted on morning of procedure. For elective sphincterotomy, the guidelines suggest discontinuation of oral anticoagulation 2-5 days before intervention (depending on the anticoagulant used and patients renal function), with bridging therapy reserved for patients who have a high-risk condition that is being treated with warfarin. In patients taking clopidogrel for a high-risk heart condition, liaison with a cardiologist is advised prior to discontinuation.

\section{Role of access papillotomy}

2008, amended 2016

Competency in access papillotomy is suggested for all endoscopists who perform ERCP. Training and subsequent mentorship should facilitate this. (Very low-quality evidence; weak recommendation)

Access papillotomy (previously described as precut or needle knife papillotomy) is a useful adjunct to endoscopic biliary cannulation in cases where access is difficult. Previous guidance has stressed the need for this technique to be restricted to those who are expert in its use in view of a higher incidence of complication. ${ }^{1}$ The current guideline recognises that most clinicians performing ERCP will wish to employ access papillotomy in selected cases. It is therefore suggested that endoscopists who perform ERCP acquire sufficient experience during their period of training and mentorship to be able to identify when access papillotomy is indicated and safely perform the procedure.

\section{Endoscopic papillary balloon dilation} New 2016

As an adjunct to biliary sphincterotomy, EPBD is recommended as a technique to facilitate removal of large CBDS. (Highquality evidence; strong recommendation)

\section{New 2016}

EPBD without prior biliary sphincterotomy is associated with an increased risk of PEP but may be considered as an alternative to biliary sphincterotomy in selected patients, such as those with an uncorrected coagulopathy or difficult biliary access due to altered anatomy. If EPBD is performed without prior biliary sphincterotomy, use of an $8 \mathrm{~mm}$ diameter balloon is recommended. (Moderate-quality evidence; strong recommendation)

Studies over the last decade confirm EPBD for larger stones may be a safe and effective technique provided that dilation is performed following prior sphincterotomy. ${ }^{100} 101$ Systematic review of meta-analyses suggests that, in patients with large stones, EPBD with sphincterotomy can reduce the need for mechanical lithotripsy and may be associated with a lower rate of overall complications compared with sphincterotomy alone. ${ }^{102}$ Technical aspects of its use are important. Balloons $>10 \mathrm{~mm}$ in diameter are usually used, though it is generally accepted that endoscopists should avoid dilating the sphincter beyond the diameter of the bile duct above. Most practitioners also advise caution in dilating to $>18 \mathrm{~mm}$. In conjunction with balloon stone extraction and mechanical lithotripsy, EPBD with prior sphincterotomy has an important role to play in the management of large CBDS. ${ }^{76}$

EPBD without prior sphincterotomy has also been described in the management of CBDS. It fell out of general favour in view of an increased risk of pancreatitis and poorer rates of stone clearance (with higher requirements for mechanical lithotripsy) compared with sphincterotomy. ${ }^{79} 103 \quad 104$ Recently, its role has been reconsidered, based on new meta-analyses, ${ }^{105-108}$ with evidence of similar rates of success and overall complication for the removal of small $(<8 \mathrm{~mm})$ bile duct stones. Meta-analysis has also suggested relative risks of cholecystitis and recurrent CBDS may be lower in patients undergoing EPBD as opposed to biliary sphincterotomy. ${ }^{108}$ Most studies analysed used an $8 \mathrm{~mm}$ diameter balloon regardless of CBD diameter, with longer duration balloon dilation ( $>1 \mathrm{~min}$ to $5 \mathrm{~min}$ ) being reported as the safest technique. ${ }^{106}$ It is important to note that the success rates quoted for EPBD in recent meta-analyses included patients randomised to EPBD who subsequently underwent rescue sphincterotomy. In addition, there are a number of accepted contraindications to EPBD without prior sphincterotomy, including biliary strictures or malignancy, previous biliary surgery (other than cholecystectomy), cholangitis, pancreatitis, prior access papillotomy and large CBDS (usually defined as $>12 \mathrm{~mm}$ ). ${ }^{105}$ The GDG felt that the increased risk of PEP remained an important limitation to recommending EPBD without prior sphincterotomy, but that it did have a role in routine clinical practice, and in particular could be considered where the risk of biliary sphincterotomy was increased, either because of coagulopathy that could not be readily corrected or anatomical factors such as a papilla within a diverticulum.

\section{Role of cholangioscopy}

\section{New 2016}

It is recommended that cholangioscopy-guided EHL or LL be considered when other endoscopic treatment options fail to achieve duct clearance. (Low-quality evidence; strong recommendation)

Per oral cholangioscopy allows endoscopic visualisation within the biliary tree and offers the potential to perform lithotripsy under direct vision using electrohydraulic or laser energy. Early studies used a 'mother and baby' system, which required two operators, was technically challenging and the cholangioscope broke easily. While it was clear that stones could be treated effectively, ${ }^{109}$ the above limitations restricted its widespread use and interest in the technique was limited. 
The introduction of new technologies has rekindled interest in cholangioscopy. The SpyGlass Legacy (Boston Scientific, Natick, Massachusetts, USA) cholangioscope was introduced in 2006 and allows a single-operator cholangioscopy (SOC) to be performed using a disposable cholangioscope, incorporating a fibre optic visualisation system, passed through the duodenoscope. Insertion of accessories through the scope may be a challenge, and the fibre optic visualisation has also been criticised. These concerns may be addressed by a new Spyglass DS digital platform introduced in 2015. In direct per oral cholangioscopy, an ultra-slim video upper GI endoscope is steered through a biliary sphincterotomy and into the bile duct. While image quality is excellent, the major difficulty with this technique is stability of the endoscope within the bile duct due to the duodenal loop. When using this method, the air or $\mathrm{CO}_{2}$ supply is switched off while cholangioscopy is being performed to reduce the risk of gas embolism.

The principle of EHL is the generation of a shock wave following the rapid thermal expansion of a fluid caused by a highvoltage spark. A subsequent hydraulic pressure wave causes stone fragmentation. In LL, pulsed laser energy is focused on the stone. The thermal effect that is absorbed by the water contained in stones causes expansion and a shock wave that causes fragmentation. The delivery of such energy needs to be conducted under direct vision to ensure safety and precise targeting during fragmentation.

In patients in whom clearance of CBDS has been unsuccessful (despite the use of techniques including mechanical lithotripsy and EPBD with prior sphincterotomy), SOC-guided intraductal lithotripsy using both EHL and LL results in very high stone clearance rates $(73-97 \%){ }^{110-112}$ Similarly, high rates of stone clearance have been reported for direct cholangioscopy, albeit in smaller studies. ${ }^{113}$ Cholangioscopy is safe but cholangitis has been reported to occur in up to $9 \%$ of patients, ${ }^{112}$ necessitating the use of prophylactic antibiotics. Otherwise complications are comparable to conventional ERCP. ${ }^{114}$ Cholangioscopy-guided lithotripsy is an important advance in the management of CBDS and is a useful strategy for patients in whom standard techniques fail.

\section{SURGICAL MANAGEMENT OF CBDS Introduction}

Surgical extraction of CBDS at the same time as (laparoscopic) cholecystectomy offers the opportunity to definitively treat gallstone-related disease in a single-stage procedure. Operator, patient and procedure related factors all influence outcome.

\section{Required facilities and personnel}

Although in a minority of patients there remains an important requirement for open surgical treatment, laparoscopic cholecystectomy has superseded open cholecystectomy as the operation of choice for symptomatic gallstones.

Over $95 \%$ of gall bladders are now removed laparoscopically, ${ }^{115}$ and more recently the technique of LBDE has become more widely available. LBDE requires (in most cases) a flexible choledochoscope together with light source and camera, and disposable instrumentation similar to that required for ERCP (eg, baskets, balloons, stents). Although open bile duct exploration can be carried out without a choledochoscope, because of the risks involved with blind instrumentation of the bile duct (ie, perforation and traumatisation with increased risk of later stricture development), bile duct exploration should always be undertaken with a choledochoscope unless no alternative is available.
There is a significant learning curve for laparoscopic bile duct surgery, both among surgeons and nursing staff. ${ }^{116}$ In the UK, centralisation of hepatopancreatobiliary resectional surgery into a defined number of units (currently 22) has allowed for the development of LBDE not only within those specialised units but also among benign upper GI surgeons in non-resection centres.

\section{Investigation of the CBD prior to surgical exploration New 2016}

IOC or LUS can be used to detect CBDS in patients who are suitable for surgical exploration or postoperative ERCP. Although not considered mandatory for all patients undergoing cholecystectomy, IOC or LUS is suggested for those patients who have an intermediate to high pre-test probability of CBDS and who have not had the diagnosis confirmed preoperatively by USS, MRCP or EUS. (Low-quality evidence; weak recommendation)

The standard way of imaging the CBD intraoperatively is by IOC, which involves transcystic cannulation of the CBD with a fine catheter and direct injection of non-ionic contrast into the bile duct. LUS is an alternative modality but is not as widely available. Both tests show high sensitivity. The IOC rate in the UK varies widely between surgeons but overall is around $10 \% .{ }^{115}$ The advantages of routine or selective IOC have been extensively debated in the literature, and the reader is directed to the 2008 guidance on management of $\mathrm{CBDS}^{1}$ for a full description of the role of IOC at the time of laparoscopic cholecystectomy. RCTs of IOC versus no IOC in patients judged to be at low risk of $\mathrm{CBDS}^{17-2026}$ suggest the use of preoperative results to select patients for further imaging is an acceptable strategy, although it is recognised that some clinicians may opt to perform an IOC in all patients undergoing cholecystectomy.

\section{Surgical bile duct exploration versus endoscopic duct clearance \\ 2016}

It is recommended that, in patients undergoing laparoscopic cholecystectomy, transcystic or transductal LBDE is an appropriate technique for CBDS removal. There is no evidence of a difference in efficacy, mortality or morbidity when LBDE is compared with perioperative ERCP, although LBDE is associated with a shorter hospital stay. It is recommended that the two approaches are considered equally valid treatment options. (High-quality evidence; strong recommendation)

\section{New 2016}

It is suggested that training of surgeons in LBDE is to be encouraged in order to decrease the number of interventions required to manage CBDS. (Low-quality evidence; weak recommendation)

In patients undergoing laparoscopic cholecystectomy, LBDE allows for single-stage treatment of CBDS with removal of the gall bladder as part of the same procedure. There are now a sufficient number of studies to determine that there is no significant difference in clinical outcomes ${ }^{77} 117118$ between LBDE and laparoscopic cholecystectomy combined with preoperative or postoperative ERCP. Studies have shown that single-stage LBDE is associated with a reduction in overall hospital stay and cost compared with the two-stage approach of ERCP and laparoscopic cholecystectomy. ${ }^{119}{ }^{120}$ It should be noted that there is some evidence to suggest that endoscopic sphincterotomy and stone clearance at the time of laparoscopic cholecystectomy is 
also cost saving and may be associated with a lower incidence of complication compared with preoperative ERCP. ${ }^{28}{ }^{121}$ The GDG recognised intraoperative ERCP as a valid treatment option for CBDS but acknowledged the logistic challenges of providing this service on a routine basis. The complications of surgical duct exploration are predominantly related to choledochotomy (bile duct leakage) and T-tube use (bile leakage, tube displacement). Pancreatitis is rare unless there has been antegrade instrumentation of the papilla. ${ }^{122}$

T-tubes were traditionally inserted in open bile duct exploration because of the risk of bile leakage from the choledochotomy, which arose as a result of uncertainty regarding duct clearance (in the absence of choledochoscopy), or because of the presence of oedema and inflammation as a result of blind instrumentation of the duct. LBDE with optical magnification, direct visualisation and more delicate instrumentation allows reduced trauma to the bile duct and has resulted in an increasing tendency to close the duct primarily. This avoids the morbidity associated with T-tubes, which includes the discomfort of managing 10-14 days with a T-tube through the abdominal wall, the risk of inadvertent early T-tube removal resulting in bile leakage, peritonitis and reoperation, and the need for postoperative T-tube cholangiograms. In addition, a small number of bile ducts leaks occur following planned removal of the T-tube and this can necessitate repeat laparotomy. Several studies have shown that primary duct closure without T-tube insertion is superior to planned T-tube insertion with reductions in hospital stay and a similar number of bile leaks and recurrent stones. ${ }^{123}$ In addition, primary duct closure is associated with a shorter operative time and faster return to work of around 8 days. ${ }^{124}$

In terms of operative technique, LBDE can be performed under image intensifier control or with the use of an ultra-thin choledochoscope $(3 \mathrm{~mm})$. It may involve a transcystic or transductal approach. The transcystic approach is more limited allowing retrieval of only small stones and poor access to the common hepatic duct. Consequently, the majority of surgeons use the transductal approach directly through the CBD. Regardless of exact technique used, the high rates of duct clearance reported with $\mathrm{LBDE}^{119} 120125-129$ can be increased to near $100 \%$ with the availability of intraductal piezoelectric or LL. ${ }^{130}$ Long-term results also appear favourable. ${ }^{131}{ }^{132}$ In patients undergoing laparoscopic cholecystectomy, transcystic or transductal exploration of the CBD is therefore considered an appropriate technique for CBDS removal. It is estimated that only $20 \%$ of bile duct explorations are performed laparoscopically at the present time, ${ }^{115}$ with findings from a 2005 survey of English hospitals suggesting less than one in three units treat patients using this technique. ${ }^{133}$ Given that ERCP and laparoscopic cholecystectomy involves two procedures (unless the former can be performed intraoperatively), it is suggested that surgeons are trained in LBDE in order to decrease the number of interventions required to manage CBDS.

\section{MANAGEMENT OF 'DIFFICULT' DUCTAL STONES Introduction \\ New 2016}

Laparoscopic duct exploration and ERCP (supplemented by EPBD with prior sphincterotomy, mechanical lithotripsy or cholangioscopy where necessary) are highly successful in removing CBDS. It is recommended that percutaneous radiological stone extraction and open duct exploration should be reserved for the small number of patients in whom these techniques fail or are not possible. (Low-quality evidence; strong recommendation)
Extraction of ductal stones via an endoscopic biliary sphincterotomy or laparoscopic route may be difficult for a variety of reasons. In most situations, size, shape and number of stones are the key determinants of whether extraction will be easy or not. The likelihood of successful extraction can also be reduced in patients who have altered anatomy as result of previous surgery (see section on stone extraction in patients with altered anatomy). Where standard stone extraction techniques supplemented by mechanical lithotripsy, EPBD with prior sphincterotomy and cholangioscopy (or, where available, extracorporeal shock wave lithotripsy) fail to remove stones, the patient can be considered to have difficult stone disease. For the small number of individuals in whom problems persist despite deploying the above techniques, percutaneous stone extraction and open duct exploration are sometimes necessary and should be considered when less invasive options fail or are not possible.

In this context, percutaneous CBDS extraction is usually achieved by establishing either a transhepatic, or less commonly, transcholecystic biliary fistula through which catheter and cholangioscopic interventions are performed. Exact methods vary, but a typical procedure will involve balloon dilation of the biliary sphincter, which allows stones to be pushed in an antegrade fashion into the duodenum, although larger calculi will require lithotripsy (either mechanical, electrohydraulic or laser). Completion rates are high but adverse events can occur with two recently published large series reporting major complications in $3.6-6.8 \%$ of patients. ${ }^{134} 135$

\section{Failed endoscopic cannulation of the CBD New 2016}

When endoscopic cannulation of the bile duct is not possible with standard techniques including access papillotomy, it is recommended that percutaneous or EUS-guided procedures can be considered as a means of facilitating subsequent ERCP. (Low-quality evidence; strong recommendation)

Even the most skilled endoscopist will fail to achieve deep biliary cannulation in a minority of cases. Clinicians should be aware of the role of combined procedures to achieve access to biliary system. Typically these involve image-guided percutaneous insertion of a catheter into the biliary system via the intrahepatic ducts or gall bladder, through which a guidewire is introduced into the duodenum. This can then be used by an endoscopist to achieve retrograde cannulation.

More recently, EUS-guided biliary drainage has been described as an alternative to percutaneous intervention. ${ }^{136}$ Two main forms of EUS-guided drainage have been reported. The first involves accessing the extrahepatic ducts, which is usually performed via the duodenum. The second involves accessing the intrahepatic ducts, which usually involves puncture of the left lobe of the liver via the stomach. Once biliary access has been achieved, the endoscopist can then pass a wire to facilitate treatment, which can be performed in an antegrade fashion or combined with ERCP and retrograde therapy. A recent meta-analysis of (predominantly) retrospective cohort studies suggests this is a valid management option for biliary strictures. ${ }^{137}$ While appropriately trained clinicians may wish to consider EUS-guided access for selected cases of CBDS, it should be noted that there are limited data on its role in this setting and at present there are few centres that have the facilities and expertise to employ this approach routinely. 


\section{Stenting as treatment for CBDS 2016}

It is important that endoscopists ensure adequate biliary drainage is achieved in patients with CBDS that have not been extracted. The short-term use of a biliary stent followed by further endoscopy or surgery is recommended. (Moderatequality evidence; strong recommendation)

\section{6}

The use of a biliary stent as sole treatment for CBDS should be restricted to a selected group of patients with limited life expectancy and/or prohibitive surgical risk. (Moderate-quality evidence; strong recommendation)

Bacterial contamination of bile is a common finding in patients with CBDS and incomplete duct clearance may therefore place patients at risk of cholangitis. ${ }^{138}$ It is therefore important that endoscopists ensure adequate biliary drainage is achieved in patients with CBDS that cannot be retrieved. The short-term use of an endoscopic biliary stent followed by further ERCP or surgery has been shown to be a safe management option in this setting. ${ }^{139}$

For patients $>70$ years of age or with debilitating disease, biliary stenting has also been examined as an alternative to endoscopic stone extraction. ${ }^{139}{ }^{140}$ The technique compares favourably with conventional stone extraction techniques in terms of immediate success and complication rate. However, at least a quarter of patients experience recurrent cholangitis during follow-up. Long-term results are probably more favourable in those patients without a gall bladder. ${ }^{140}$ More recently, a study from Italy looked at the management of long-term stents in patients with CBDS that were difficult to remove by conventional means. Over a mean follow-up period of 14 months, there was a $36 \%$ cholangitis rate in patients who had stents changed on demand with an associated mortality of $8 \%$. Patients who had stents changed electively at three monthly intervals had an $8 \%$ cholangitis rate and $2 \%$ mortality. ${ }^{141}$ As such, patients faced a high risk of complication or multiple interventions.

In light of the above findings, biliary stenting is recommended as a means of ensuring adequate biliary drainage in patients for whom further therapy is planned. However, stenting as definitive treatment for CBDS should be restricted to a very few patients who have limited life expectancy or are judged to be at prohibitive surgical risk. Clearance of bile duct stones should be considered the standard of care, ${ }^{28}$ and patients should be referred to specialist centres for consideration of surgery or advanced endoscopic therapy if stones cannot be removed using standard stone extraction techniques.

\section{MANAGEMENT OF CBDS IN SPECIFIC CLINICAL SETTINGS Introduction}

Laparoscopic cholecystectomy and ERCP are now mature technologies, and in some areas of practice, there has been no major change in recommendations in comparison to the 2008 guideline. Areas where advice has changed include treatment of acute gallstone pancreatitis.

\section{Management of patients with and without a gall bladder New 2016}

Cholecystectomy is recommended for all patients with CBDS and gall bladder stones unless there are specific reasons for considering surgery inappropriate. (High-quality evidence; strong recommendation)
Where operative risk is deemed prohibitive, biliary sphincterotomy and endoscopic duct clearance alone is recommended as an acceptable alternative. (Low-quality evidence; weak recommendation)

\section{8}

Biliary sphincterotomy and endoscopic stone extraction is recommended as the primary form of treatment for patients with CBDS post cholecystectomy. (Low-quality evidence; strong recommendation)

For patients with gall bladder stones and stones in the CBD, there is a risk of cholecystitis and/or stone migration following duct clearance. A Cochrane review published in $2007^{142}$ addressed the question as to whether prophylactic cholecystectomy should be offered to patients whose gall bladder remains in situ after endoscopic sphincterotomy and CBD clearance. Systematic review identified five randomised trials involving 662 participants. The studies included both open cholecystectomy and exploration, ${ }^{143-145}$ and laparoscopic cholecystectomy, ${ }^{146} 147$ as the surgical intervention of choice. Meta-analysis indicated that over a follow-up period that varied between an average of 17 months to over 5 years mortality was higher in the wait and see group than in the prophylactic cholecystectomy group (14.1\% vs $7.9 \%$; relative risk $1.78,95 \%$ CI 1.15 to 2.75$)$ and that the benefit of surgery persisted when analysis was restricted to those studies that included patients at higher surgical risk, as defined by an American Society of Anaesthesiology score of 4 or $5 .^{143-145} 148$ Secondary end points of recurrent pain, jaundice and cholangitis were also significantly more common in the wait and see group. Two more randomised trials have been published since this meta-analysis. In one, prophylactic cholecystectomy after CBDS extraction was compared with a policy of leaving calculous gall bladders in situ. Prophylactic cholecystectomy reduced the incidence of subsequent cholecystitis but not cholangitis. ${ }^{149}$ However, only 90 participants were included and the study was limited by significant crossover between the allocated treatment arms. In the second study, ${ }^{150}$ 162 participants, all of whom were over the age of 70 years and had coexisting gall bladder stones, were randomised to wait and see or cholecystectomy after successful endoscopic duct clearance. A significant reduction in total biliary events (which included cholangitis) was seen in the group undergoing elective cholecystectomy.

Uncertainty persists as to whether the recommendation to offer cholecystectomy to patients with gall bladder stones and CBDS should be extended to individuals with CBDS but an empty gall bladder on imaging. Several large observational studies have examined the importance of gall bladder status in Asian patients who have undergone successful endoscopic duct clearance. ${ }^{151-153}$ Over a period of follow-up that varied from a median of 34 months ${ }^{151}$ to 15 years, ${ }^{153}$ these studies reported recurrent CBDS in $15-23.7 \%$ of patients with residual gall bladder stones. This contrasted with patients who had an empty gall bladder in situ, where the reported incidence of recurrent CBDS was significantly lower at $5.9 \%{ }^{152}$ to $11.3 \% .^{153}$ In contrast, smaller studies of both Asian ${ }^{154-157}$ and European patients ${ }^{158-160}$ have not been able to clearly demonstrate a higher likelihood of recurrent CBDS following duct clearance in patients with gall bladder stones. However, several reports suggest that patients with an empty gall bladder have a lower risk of cholecystitis and subsequent cholecystectomy. ${ }^{155} \quad 158 \quad 160$ Surgeons may therefore wish to discuss a wait and see approach with patients who have an empty gall bladder following duct clearance. 
Despite the benefits of cholecystectomy, the operative risk for some patients will be judged prohibitive. Given that age and comorbidity do not appear to have a significant impact on overall complication rates for ERCP, ${ }^{161-164}$ biliary sphincterotomy and endoscopic duct clearance alone is an acceptable alternative for this group.

While there is no formal comparison of endoscopic versus surgical extraction of CBDS in patients who have undergone previous cholecystectomy, the minimally invasive nature of ERCP means that this remains the primary form of treatment in this setting and no change has been made to the recommendation for this category of patients.

\section{Management of cholangitis \\ New 2016}

Patients with acute cholangitis who fail to respond to antibiotic therapy or who have signs of septic shock require urgent biliary decompression. Endoscopic CBDS extraction and/or biliary stenting are recommended in this setting. If ERCP is not possible, percutaneous radiological drainage can be considered as an alternative. (Moderate-quality evidence; strong recommendation)

Historic data suggest that the risks of emergency biliary surgery in older patients can be significant, ${ }^{165-168}$ and in the context of acute cholangitis the role of ERCP is now well established. ${ }^{169}$ High-quality data on the optimal timing of ERCP in this setting are lacking but early intervention is likely to be beneficial. A recent prospective study of 199 patients admitted to hospital with acute cholangitis found that for each day that ERCP was delayed length of stay increased by 1.44 days $(95 \%$ CI 1.01 to 1.92 ). The study also identified an increased requirement for vasopressors in patients who had ERCP performed $>72$ hours after presentation. ${ }^{170}$ For patients with signs of septic shock or who are deteriorating despite appropriate antibiotic therapy, biliary decompression may need to be achieved urgently (ie, within 24 hours of presentation). As described in previous guidance, in circumstances where ERCP fails or is unavailable percutaneous biliary drainage is an alternative form of treatment.

\section{Acute gallstone pancreatitis}

New 2016

Patients with pancreatitis of suspected or proven biliary origin who have associated cholangitis or persistent biliary obstruction are recommended to undergo biliary sphincterotomy and endoscopic stone extraction within 72 hours of presentation. (High-quality evidence; strong recommendation)

\section{New 2016}

It is recommended that following gallstone pancreatitis early laparoscopic cholecystectomy should be offered to all patients on whom it is safe to operate as the most effective means to prevent recurrent episodes. (Moderate-quality evidence, strong recommendation)

\section{New 2016}

In cases of mild acute gallstone pancreatitis, it is advised that cholecystectomy should be performed within 2 weeks of presentation and preferably during the same admission. (Moderatequality evidence; weak recommendation)

\section{New 2016}

It is recommended that patients with gallstone pancreatitis who do not require ERCP within 72 hours of presentation should be considered for elective ERCP and endoscopic sphincterotomy if there is evidence of retained CBDS on imaging or the patient is unsuitable for definitive treatment in the form of cholecystectomy. (Moderate-quality evidence; strong recommendation)

CBDS are a common cause of acute pancreatitis. A biliary aetiology for pancreatitis may be suggested by LFT abnormalities; the presence of gall bladder stones, ductal stones or bile duct dilatation on imaging; or coexistent cholangitis. In such cases, the timing and selection of patients for endoscopic stone extraction is important. Studies to date have produced conflicting evidence and guidelines have also supported varied approaches. This is reflected in the reported variation in clinical practice from extant guidelines. ${ }^{171} 172$

A recent Cochrane review ${ }^{173}$ has found no evidence that early routine biliary sphincterotomy \pm endoscopic stone extraction significantly affects mortality or complications regardless of the severity of the pancreatitis. The analysis did support a strategy of early biliary sphincterotomy \pm endoscopic stone extraction in patients with cholangitis or biliary obstruction.

There is heterogeneity in studies as to what constitutes 'early' ERCP, with variation from $<24$ to $<72$ hours following admission. There is no evidence to support ERCP within 24 hours rather than ERCP within 72 hours. However, no studies have been designed to answer this question. It is therefore recommended that patients with pancreatitis of suspected or proven biliary origin with associated biliary obstruction or cholangitis should undergo biliary sphincterotomy \pm endoscopic stone extraction within 72 hours of presentation. Within this group of patients, clinicians should be alert to individuals with severe sepsis in whom optimal management may involve urgent ERCP within 24 hours, as described in the preceding section. Conversely, it is recognised that a number of cases of jaundice without sepsis may resolve or improve significantly over a period of 24-72 hours. In this situation, early ERCP can be avoided, although the clinician should consider additional imaging (MRCP, EUS, IOC or LUS) to exclude retained ductal stones and help decide whether biliary sphincterotomy is required to reduce the likelihood of future problems as described below.

In patients with an in situ gall bladder, an episode of gallstone pancreatitis is associated with a significant risk of recurrent attacks as well as a smaller risk of biliary colic and cholecystitis. ${ }^{174-176}$ These risks can be reduced by removal of the gall bladder. Following mild gallstone pancreatitis, laparoscopic cholecystectomy within 2 weeks of presentation and ideally during the same admission should be considered the preferred option. ${ }^{177}$ This may not be possible for patients with significant comorbidities or acute severe pancreatitis, where removal of the gall bladder should be deferred until it is safe to operate. In patients who are unable to undergo cholecystectomy, consideration should be given to elective biliary sphincterotomy. A recent systematic review of published studies and international guidelines suggests this significantly reduces the risk of recurrent pancreatitis but is a less effective strategy than cholecystectomy, particularly in relation to preventing other biliary complications. ${ }^{178}$

The greatest reduction in risk of recurrent events may be seen when patients undergo both sphincterotomy and cholecystectomy. ${ }^{179}$ As such, patients who require sphincterotomy and duct clearance in the context of acute gallstone pancreatitis should still be considered for subsequent laparoscopic cholecystectomy, ${ }^{142}$ although there is currently insufficient evidence to recommend routine biliary sphincterotomy for all patients listed for laparoscopic cholecystectomy following mild acute gallstone pancreatitis. 


\section{Stone extraction in patients with altered anatomy} New 2016

ERCP for CBDS extraction can be successfully performed in patients with Billroth II anatomy. Where ERCP with a duodenoscope is difficult, use of a forward viewing endoscope is recommended. (Moderate-quality evidence; weak recommendation).

In cases where biliary sphincterotomy cannot be safely completed, a limited sphincterotomy supplemented by EPBD is suggested as an alternative. (Low-quality evidence; weak recommendation)

\section{New 2016}

Patients with RYGB and CBDS should be referred to centres that are able to offer the advanced endoscopic and surgical treatment options that are necessary for stone extraction. (Low-quality evidence; weak recommendation)

The endoscopic management of bile duct stones in patients with altered upper GI anatomy presents a significant challenge. The difficulties in reaching the papilla, accessing the bile duct and delivering appropriate therapy are factors that may reduce the likelihood of a successful procedure. The two common postsurgical states encountered are patients with Billroth II type gastrectomies and patients whom have undergone a gastric bypass with Roux-en-Y formation. The almost complete cessation of surgery for chronic peptic ulceration has resulted in a marked decline in number of patients with a Billroth II type gastrectomy, whereas the number of patients undergoing obesity surgery (which includes RYGB) is rapidly increasing. This guideline will concentrate on these two clinical states. The subject, including technological considerations, has recently been comprehensively reviewed. ${ }^{180} 181$

\section{Billroth II gastrectomy}

Many experts believe that in the presence of an intact papilla the use of a side-viewing duodenoscope facilitates both cannulation and subsequent therapy because of the elevator and large accessory channel. A forward-viewing endoscope however has advantages of flexibility and luminal visualisation that makes it possible to reach the papilla in Billroth II patients when an approach with a duodenoscope has failed.

The single RCT that has compared forward-viewing endoscopes with conventional duodenoscopes demonstrated a higher success rate with forward-viewing endoscopes (87\% vs 68\%) and a higher complication rate with duodenoscopes (namely an $18 \%$ visceral perforation rate). ${ }^{182}$ This has not been confirmed by other reports that have described a perforation rate of 2.710\%. ${ }^{183}{ }^{184}$ An approach of duodenoscope first followed by forward-viewing endoscope if there is initial failure is a reasonable strategy.

The 'upside-down' (5 o'clock) orientation of the papilla when approached from the afferent limb after Billroth II gastrectomy requires a significant alteration in sphincterotomy technique. Successful outcomes can be achieved by using sphincterotomes that have been modified to alter the orientation of the cutting wire or by using conventional sphincterotomes that can be rotated. However, in some cases safe, effective orientation of the cutting wire cannot be achieved. As a consequence, it is not always possible to perform the full sphincterotomy that is required for successful removal of stones. Biliary sphincterotomy using a needle knife, with a straight plastic stent as a guide, is an alternative method that has been described in a number of series. Compared with EPBD, it is reported to have equal efficacy. ${ }^{185}$ As discussed in previously, there remain concerns about the risk of pancreatitis in patients undergoing EPBD without prior sphincterotomy. An approach that combines limited biliary sphincterotomy with a needle knife over a straight plastic biliary stent or guidewire, followed by EPBD and conventional stone extraction, has been reported. ${ }^{186}$ It is becoming the method preferred by experts, and potentially combines ease of use, safety and efficacy.

\section{Roux-en-Y gastric bypass}

The rapidly increasing health burden of obesity is driving an increase in bariatric surgery. Gallstone disease is a significant problem in the obese population and also in patients who have undergone weight loss procedures, of which the most commonly performed is a laparoscopic RYGB.

The long afferent limb of the RYGB that is deliberately fashioned at surgery effectively means that the only endoscopes that can be used in a conventional per-oral retrograde approach are enteroscopes with either a single or double balloon, or a spiral overtube. Selection and use of accessories is difficult, both because of the narrower working channels and length of the enteroscope. A large retrospective series compared enteroscopic techniques in 129 patients with Roux-en-Y reconstruction, of which 63 had post- RYGB anatomy with an intact papilla. Successful ERCP was achieved in $63 \%$ of these patients with a $12 \%$ complication rate. ${ }^{187}$ There was no significant difference in outcomes according to the enteroscopic technique used.

Alternative techniques have been described that use the intact antroduodenal pathway from the excluded stomach to the papilla. These require a large gastrostomy through which a duodenoscope can be passed. The gastrostomy can be created by performing a long-limb enteroscopy to the stomach followed by a conventional percutaneous approach or by use of an interventional radiological technique with assistance from an EUS-guided puncture from the gastric remnant. More recently, the technique of EUS-guided puncture from the gastric remnant followed by placement of a self-expanding lumen-apposing metal stent has been described. This allows for immediate per-oral access to the papilla. These are all complex procedures, reported in small series using endoscopic techniques that are highly specialised. ${ }^{188-190}$

Laparoscopically assisted ERCP in post-RYGB patients is a technique that has been reported in larger numbers and the individual component techniques and skills are more readily available. A laparoscopic gastrostomy is created and at the same session ERCP is performed following which the gastrostomy is closed. A retrospective series from the USA compared this technique to long-limb enteroscopy in 56 patients. ${ }^{191}$ The therapeutic success rate for laparoscopic-assisted ERCP was $100 \%$ versus $59 \%$ in the enteroscopy group. There was no difference in hospital stay or complications in either group. Although there are organisational challenges with this technique, it is probably the best option currently and could be delivered by the majority of larger volume secondary care units.

\section{IMPLICATIONS FOR SERVICE ORGANISATION AND TRAINING}

Delivery of the achievable aims for ERCP service provision and training will require organisations to review the way their services are provided. Key performance indicators in the BSG standards framework ${ }^{75}$ include having sufficient capacity to deliver ERCP 52 weeks a year; adequate interventional radiology support; access to anaesthesia-supported ERCP and regular morbidity and mortality meetings that are able to demonstrate outcomes that meet minimum standards. To achieve some of these 
key performance indicators will involve hospitals working collaboratively in the context of operational networks. While additional resources will be needed in some areas, there is also the potential to avoid the costs incurred by delayed intervention, adverse events, repeat procedures and prolonged hospital stays.

Similarly, if LBDE is to be made available to all patients who could potentially benefit there will need to be a sufficient number of trained surgeons and service planning will need to reflect this.

Intraoperative ERCP is a valid alternative to LBDE, but it is recognised that coordinating the relevant specialty teams and resources to deliver this on a routine basis within the National Health Service would require improved integration of medical and surgical gastroenterology services.

\section{RESEARCH RECOMMENDATIONS}

Many of the recommendations contained within these guidelines are based on limited evidence, and conducting large-scale head-to-head comparisons of different diagnostic and therapeutic strategies remains difficult. Opportunities for further research still exist in many areas, including

Studies that use adequate periods of clinical follow-up to assess the diagnostic accuracy CBDS diagnosis using clinical, LFT and USS findings in combination.

Studies of the natural history of CBDS, particularly in asymptomatic patients in whom extraction is not performed.

Randomised control study of MRCP versus EUS in the diagnosis of suspected CBDS.

Studies to define minimum standards/key performance indicators for services offering endoscopic and surgical CBDS clearance.

The features of a high-quality service as measured by patients being treated for CBDS.

Studies to establish the optimum treatment algorithm for removal of large CBDS.

Studies to clarify the harm/benefit of routine IOC in patients with low risk of CBDS.

Studies to clarify the role of pancreatic duct stenting in patients receiving rectal NSAIDS.

Acknowledgements This guideline has been reviewed and endorsed by The Faculty of Clinical Radiology of The Royal College of Radiologists.

Contributors The following all contributed to the manuscript as members of the guideline development group. Specific responsibilities were as follows: Peggy and Hannah Anderson. Patient representatives, approached via British Liver Trust. Reviewed draft and commented on recommendations relevant to patient experience. IB, lead author for section on surgical management of CBDS; coordinated feedback from surgical societies. GES, reviewed draft as a GI trainee and was responsible for initial literature search. KG provided critical review of evidence and methodology based on personal research and participation in other guideline development groups. Co-author for sections relating to development process for current guidelines; identifying individuals with CBDS and surgical management of CBDS. RS, lead author for sections relating to management of "difficult" ductal stones and management of CBDS in specific clinical settings. GW, lead author for section relating to endoscopic management of CBDS: EW, Chair of GDG and lead author for introductory and concluding sections, including those relating to general principles in management of CBDS and identification of individuals with CBDS. Responsible for editing contributions and document management. TY, co-author of section on identifying individuals with CBDS. Responsible for coordinating feedback from radiological societies.

Competing interests GW has sat on the Advisory Board for Cook Medical and Boston Scientific. He has received help from both companies in order to deliver live endoscopy courses and has had financial support to cover the costs of attending national and international meetings as a speaker. RS sits on the Advisory Board for Boston Scientific.

Provenance and peer review Not commissioned; externally peer reviewed.

\section{REFERENCES}

1 Williams EJ, Green J, Beckingham I, et al. Guidelines on the management of common bile duct stones (CBDS). Gut 2008;57:1004-21.
2 Brouwers MC, Kho ME, Browman GP, et al. AGREE II: advancing guideline development, reporting and evaluation in health care. CMAJ 2010;182: E839-42.

3 GRADE criteria. http://www.gradeworkingpartygroup.org (accessed 01/06/2014)

4 Brozek JL, AkI EA, Alonso-Coello P, et al. Grading quality of evidence and strength of recommendations in clinical practice guidelines. Part 1 of 3. An overview of the GRADE approach and grading quality of evidence about interventions. Allergy 2009;64:669-77.

5 Brożek JL, AkI EA, Compalati E, et al. Grading quality of evidence and strength of recommendations in clinical practice guidelines part 3 of 3 . The GRADE approach to developing recommendations. Allergy 2011;66:588-95.

6 Tazuma S. Gallstone disease: Epidemiology, pathogenesis, and classification of biliary stones (common bile duct and intrahepatic). Best Pract Res Clin Gastroenterol 2006;20:1075-83.

7 Tsui WM, Lam PW, Lee WK, et al. Primary hepatolithiasis, recurrent pyogenic cholangitis, and oriental cholangiohepatitis: a tale of 3 countries. Adv Anat Pathol 2011;18:318-28.

8 Neuhaus $\mathrm{H}$, Feussner $\mathrm{H}$, Ungeheuer $\mathrm{A}$, et al. Prospective evaluation of the use of endoscopic retrograde cholangiography prior to laparoscopic cholecystectomy. Endoscopy 1992;24:745-9.

9 Saltzstein EC, Peacock JB, Thomas MD. Preoperative bilirubin, alkaline phosphatase and amylase levels as predictors of common duct stones. Surg Gynecol Obstet 1982;154:381-4.

10 Lacaine F, Corlette MB, Bismuth H. Preoperative evaluation of the risk of common bile duct stones. Arch Surg 1980;115:1114-16.

11 Houdart R, Perniceni T, Darne B, et al. Predicting common bile duct lithiasis: determination and prospective validation of a model predicting low risk. Am J Surg 1995:170:38-43.

12 Welbourn CR, Mehta D, Armstrong CP, et al. Selective preoperative endoscopic retrograde cholangiography with sphincterotomy avoids bile duct exploration during laparoscopic cholecystectomy. Gut 1995;37:576-9.

13 Videhult P, Sandblom G, Rasmussen IC. How reliable is intraoperative cholangiography as a method for detecting common bile duct stones?: a prospective population-based study on 1171 patients. Surg Endosc 2009:23:304-12.

14 Collins C, Maguire D, Ireland A, et al. A prospective study of common bile duct calculi in patients undergoing laparoscopic cholecystectomy: natural history of choledocholithiasis revisited. Ann Surg 2004;239:28-33.

15 Nebiker CA, Baierlein SA, Beck S, et al. Is routine MR cholangiopancreatography (MRCP) justified prior to cholecystectomy? Langenbecks Arch Surg 2009:394:1005-10.

16 Lill S, Rantala A, Pekkala E, et al. Elective laparoscopic cholecystectomy without routine intraoperative cholangiography: a retrospective analysis of 1101 consecutive cases. Scand J Surg 2010;99:197-200.

17 Hauer-Jensen $M$, Kåresen $\mathrm{R}$, Nygaard $\mathrm{K}$, et al. Consequences of routine peroperative cholangiography during cholecystectomy for gallstone disease: a prospective, randomized study. World J Surg 1986;10:996-1002.

18 Soper NJ, Dunnegan DL. Routine versus selective intra-operative cholangiography during laparoscopic cholecystectomy. World J Surg 1992;16:1133-40.

19 Nies C, Bauknecht F, Groth C, et al. [Intraoperative cholangiography as a routine method? A prospective, controlled, randomized study]. Chirurg 1997;68:892-7.

20 Khan OA, Balaji S, Branagan G, et al. Randomized clinical trial of routine on-table cholangiography during laparoscopic cholecystectomy. Br J Surg 2011;98:362-7.

21 Attili AF, De Santis A, Capri R, et al. The natural history of gallstones: the GREPCO experience. The GREPCO Group. Hepatology 1995;21:655-60.

22 Halldestam I, Enell EL, Kullman E, et al. Development of symptoms and complications in individuals with asymptomatic gallstones. Br J Surg 2004;91:734-8

23 Cox MR, Budge JP, Eslick GD. Timing and nature of presentation of unsuspected retained common bile duct stones after laparoscopic cholecystectomy: a retrospective study. Surg Endosc 2015;29:2033-8.

24 Lefemine V, Morgan RJ. Spontaneous passage of common bile duct stones in jaundiced patients. Hepatobiliary Pancreat Dis Int 2011;10:209-13.

25 Balandraud P, Biance N, Peycru T, et al. Fortuitous discovery of common bile duct stones: results of a conservative strategy. Gastroenterol Clin Biol 2008;32: 408-12.

26 Murison MS, Gartell PC, McGinn FP. Does selective peroperative cholangiography result in missed common bile duct stones? J R Coll Surg Edinb 1993:38:220-4.

27 Möller M, Gustafsson U, Rasmussen F, et al. Natural course vs interventions to clear common bile duct stones: data from the Swedish Registry for Gallstone Surgery and Endoscopic Retrograde Cholangiopancreatography (GallRiks). JAMA Surg 2014;149:1008-13.

28 NICE. Gallstone Disease: Diagnosis and management. October 2014. https://www. nice.org.uk/guidance/cg188

29 Commissioning Guide: Gallstone Disease. Association of Upper Gastrointestinal Surgeons The Royal College of Surgeons of England, London. 2013.

30 Taylor A, Stapley S, Hamilton W. Jaundice in primary care: a cohort study of adults aged $>45$ years using electronic medical records. Fam Pract 2012;29:416-20. 
31 Sheen AJ, Asthana S, Al-Mukhtar A, et al. Preoperative determinants of common bile duct stones during laparoscopic cholecystectomy. Int J Clin Pract 2008;62:1715-19.

32 Corfield AP, Cooper MJ, Williamson RC. Acute pancreatitis: a lethal disease of increasing incidence. Gut 1985;26:724-9.

33 Toh SK, Phillips S, Johnson CD. A prospective audit against national standards of the presentation and management of acute pancreatitis in the South of England. Gut 2000:46:239-43.

34 Gurusamy KS, Giljaca V, Takwoingi Y, et al. Ultrasound versus liver function tests for diagnosis of common bile duct stones. Cochrane Database Syst Rev 2015;(2): CD011548.

35 Busel D, Espinoza Ugarte A, Osorio M, et al. [Ultrasonics in the diagnosis of choledocholithiasis]. Rev Med Chil 1989;117:40-1.

36 Silverstein JC, Wavak E, Millikan KW. A prospective experience with selective cholangiography. Am Surg 1998;64:654-8; discussion 658-9.

37 Kumar M, Prashad R, Kumar A, et al. Relative merits of ultrasonography, computed tomography and cholangiography in patients of surgical obstructive jaundice. Hepatogastroenterology 1998;45:2027-32.

38 Admassie $D, H /$ Yesus $A$, Denke $A$. Validity of ultrasonography in diagnosing obstructive jaundice. East Afr Med J 2005;82:379-81.

39 Rickes S, Treiber G, Mönkemüller K, et al. Impact of the operator's experience on value of high-resolution transabdominal ultrasound in the diagnosis of choledocholithiasis: a prospective comparison using endoscopic retrograde cholangiography as the gold standard. Scand J Gastroenterol 2006;41: 838-43.

40 Jovanović $\mathrm{P}$, Salkić NN, Zerem $\mathrm{E}$, et al. Biochemical and ultrasound parameters may help predict the need for therapeutic endoscopic retrograde cholangiopancreatography (ERCP) in patients with a firm clinical and biochemical suspicion for choledocholithiasis. Eur J Intern Med 2011;22:e110-14.

41 Nathan T, Kjeldsen J, Schaffalitzky de Muckadell OB. Prediction of therapy in primary endoscopic retrograde cholangiopancreatography. Endoscopy 2004;36:527-34.

42 Onken JE, Brazer SR, Eisen GM, et al. Predicting the presence of choledocholithiasis in patients with symptomatic cholelithiasis. Am J Gastroenterol 1996:91:762-7.

43 Trondsen E, Edwin B, Reiertsen O, et al. Prediction of common bile duct stones prior to cholecystectomy: a prospective validation of a discriminant analysis function. Arch Surg 1998;133:162-6.

44 Pourseidi B, Khorram-Manesh A. Triple non-invasive diagnostic test for exclusion of common bile ducts stones before laparoscopic cholecystectomy. World J Gastroenterol 2007;13:5745-9.

45 Liu CL, Lo CM, Chan JK, et al. Detection of choledocholithiasis by EUS in acute pancreatitis: a prospective evaluation in 100 consecutive patients. Gastrointest Endosc 2001;54:325-30.

46 Ang TL, Liew SFAP, Ang D, et al. EUS Guided ERCP in patients with negative cross sectional imaging but high clinical probability of choledocholithiasis. Gastrointest Endosc 2012;75(Suppl 4):AB203.

47 Boraschi P, Gigoni R, Braccini G, et al. Detection of common bile duct stones before laparoscopic cholecystectomy. Evaluation with MR cholangiography. Acta Radiol 2002;43:593-8.

48 Buscarini E, Tansini P, Vallisa D, et al. EUS for suspected choledocholithiasis: do benefits outweigh costs? A prospective, controlled study. Gastrointest Endosc 2003:57:510-18.

49 Canto MI, Chak A, Stellato T, et al. Endoscopic ultrasonography versus cholangiography for the diagnosis of choledocholithiasis. Gastrointest Endosc 1998;47:439-48.

50 Choo L, Mishra G, Conway J, et al. Prospective single blinded study of endoscopic ultrasound prior to endoscopic retrograde cholangiopanctreatography for patients for a positive intraoperative cholangiogram. Gastrointest Endosc 2012;75(Suppl 4): AB203.

51 de Lédinghen $\mathrm{V}$, Lecesne R, Raymond JM, et al. Diagnosis of choledocholithiasis: EUS or magnetic resonance cholangiography? A prospective controlled study. Gastrointest Endosc 1999:49:26-31.

52 Fazel A, Catalano MF, Quadri A, et al. A comparison of the diagnostic accuracy of EUS and ERCP in identifying common bile duct stones. Gastrointest EndosC 2002:55:AB246.

53 Fernández-Esparrach G, Ginès A, Sánchez M, et al. Comparison of endoscopic ultrasonography and magnetic resonance cholangiopancreatography in the diagnosis of pancreatobiliary diseases: a prospective study. Am J Gastroenterol 2007:102:1632-9.

54 Gautier G, Pilleul F, Crombe-Ternamian A, et al. Contribution of magnetic resonance cholangiopancreatography to the management of patients with suspected common bile duct stones. Gastroenterol Clin Biol 2004;28:129-34.

55 Guarise A, Baltieri S, Mainardi P, et al. Diagnostic accuracy of MRCP in choledocholithiasis. Radiol Med (Torino) 2005;109:239-51.

56 Jendresen MB, Thorbøll JE, Adamsen S, et al. Preoperative routine magnetic resonance cholangiopancreatography before laparoscopic cholecystectomy: a prospective study. Eur J Surg 2002;168:690-4.
57 Kohut M, Nowakowska-Duława E, Marek T, et al. Accuracy of linear endoscopic ultrasonography in the evaluation of patients with suspected common bile duct stones. Endoscopy 2002;34:299-303.

58 Miletic D, Uravic M, Mazur-Brbac M, et al. Role of magnetic resonance cholangiography in the diagnosis of bile duct lithiasis. World J Surg 2006;30:1705-12.

59 Montariol T, Msika S, Charlier A, et al. Diagnosis of asymptomatic common bile duct stones: preoperative endoscopic ultrasonography versus intraoperative cholangiography - a multicenter, prospective controlled study. French Associations for Surgical Research. Surgery 1998;124:6-13.

60 Ney MV, Maluf-Filho F, Sakai P, et al. Echo-endoscopy versus endoscopic retrograde cholangiography for the diagnosis of choledocholithiasis: the influence of the size of the stone and diameter of the common bile duct. Arq Gastroenterol 2005;42:239-43.

61 Norton SA, Alderson D. Prospective comparison of endoscopic ultrasonography and endoscopic retrograde cholangiopancreatography in the detection of bile duct stones. Br J Surg 1997;84:1366-9.

62 Prat F, Amouyal G, Amouyal P, et al. Prospective controlled study of endoscopic ultrasonography and endoscopic retrograde cholangiography in patients with suspected common-bileduct lithiasis. Lancet 1996;347:75-9.

63 Giljaca V, Gurusamy KS, Takwoingi Y, et al. Endoscopic ultrasound versus magnetic resonance cholangiopancreatography for common bile duct stones. Cochrane Database Syst Rev 2015;(2):CD011549.

64 Ledro-Cano D. Suspected choledocholithiasis: endoscopic ultrasound or magnetic resonance cholangio-pancreatography? A systematic review. Eur J Gastroenterol Hepatol 2007:19:1007-11.

65 McMahon CJ. The relative roles of magnetic resonance cholangiopancreatography (MRCP) and endoscopic ultrasound in diagnosis of common bile duct calculi: a critically appraised topic. Abdom Imaging 2008;33:6-9.

66 Schmidt S, Chevallier P, Novellas S, et al. Choledocholithiasis: repetitive thick-slab single-shot projection magnetic resonance cholangiopancreaticography versus endoscopic ultrasonography. Eur Radiol 2007:17:241-50.

67 Morris S, Gurusamy KS, Sheringham J, et al. Cost-Effectiveness Analysis of Endoscopic Ultrasound versus Magnetic Resonance Cholangiopancreatography in Patients with Suspected Common Bile Duct Stones. PLOS ONE 2015;10:e0121699.

68 De Vargas Macciucca M, Lanciotti S, De Cicco ML, et al. Ultrasonographic and spiral CT evaluation of simple and complicated acute cholecystitis: diagnostic protocol assessment based on personal experience and review of the literature. Radiol Med 2006;111:167-80.

69 Kondo S, Isayama H, Akahane $\mathrm{M}$, et al. Detection of common bile duct stones: comparison between endoscopic ultrasonography, magnetic resonance cholangiography, and helical-computed-tomographic cholangiography. Eur J Radiol 2005;54:271-5.

70 Polkowski M, Palucki J, Regula J, et al. Helical computed tomographic cholangiography versus endosonography for suspected bile duct stones: a prospective blinded study in non-jaundiced patients. Gut 1999;45:744-9.

71 Soto JA, Velez SM, Guzmán J. Choledocholithiasis: diagnosis with oral-contrastenhanced CT cholangiography. AJR Am J Roentgenol 1999;172:943-8.

72 Anderson SW, Lucey BC, Varghese JC, et al. Accuracy of MDCT in the diagnosis of choledocholithiasis. AJR Am J Roentgenol 2006;187:174-80.

73 Anderson SW, Rho E, Soto JA. Detection of biliary duct narrowing and choledocholithiasis: accuracy of portal venous phase multidetector CT. Radiology 2008:247:418-27.

74 Kim CW, Chang JH, Lim YS, et al. Common bile duct stones on multidetector computed tomography: attenuation patterns and detectability. World J Gastroenterol 2013;19:1788-96.

75 Tseng CW, Chen CC, Chen TS, et al. Can computed tomography with coronal reconstruction improve the diagnosis of choledocholithiasis? J Gastroenterol Hepatol 2008:23:1586-9.

76 Maple JT, Ikenberry SO, Anderson MA, et al. The role of endoscopy in the management of choledocholithiasis. Gastrointest Endosc 2011;74:731-44.

77 Dasari BV, Tan CJ, Gurusamy KS, et al. Surgical versus endoscopic treatment of bile duct stones. Cochrane Database Syst Rev 2013;(12):CD003327.

78 Gurusamy K, Sahay SJ, Burroughs AK, et al. Systematic review and meta-analysis of intraoperative versus preoperative endoscopic sphincterotomy in patients with gallbladder and suspected common bile duct stones. Br J Surg 2011;98:908-16.

79 Weinberg BM, Shindy W, Lo S. Endoscopic balloon sphincter dilation (sphincteroplasty) versus sphincterotomy for common bile duct stones. Cochrane Database Syst Rev 2006:CD004890.

80 Williams EJ, Taylor S, Fairclough P, et al. Are we meeting the standards set for endoscopy? Results of a large-scale prospective survey of endoscopic retrograde cholangio-pancreatograph practice. Gut 2007;56:821-9.

81 Wilkinson M, Charnley R, Morris J, et al. ERCP, The way forward. A standards framework. 2014. http://www.bsg.org.uk/clinical-guidance/endoscopy/ ercp-the-way-forward-a-standards-framework.html

82 Raymondos K, Panning B, Bachem I, et al. Evaluation of endoscopic retrograde cholangiopancreatography under conscious sedation and general anesthesia. Endoscopy 2002;34:721-6. 
83 Church N, Periera S, Hatfield A, et al. Success of initial ERCP following therapeutic failure. Gut 2007;7(Suppl II):A88.

84 Garewal D, Powell S, Milan SJ, et al. Sedative techniques for endoscopic retrograde cholangiopancreatography. Cochrane Database Syst Rev 2012;(6): CD007274.

85 Guidance for the use of propofol sedation for adult patients undergoing endoscopic retrograde cholangiopancreatography (ERCP) and other complex upper $\mathrm{Gl}$ procedures. On behalf of the Joint Royal College of Anaesthetists and British Society of Gastroenterology Working Party. 2011.

86 Kalaitzakis E, Webster GJ, Oppong KW, et al. Diagnostic and therapeutic utility of single-operator peroral cholangioscopy for indeterminate biliary lesions and bile duct stones. Eur J Gastroenterol Hepatol 2012;24:656-64.

87 Joshi D, Paranandi B, El Sayed G, et al. Experience of propofol sedation in a UK ERCP practice: lessons for service provision. Frontline Gastroenterol 2015;6:32-7.

88 Elmunzer BJ, Scheiman JM, Lehman GA, et al. A randomized trial of rectal indomethacin to prevent post-ERCP pancreatitis. N Engl J Med 2012;366:1414-22.

89 Otsuka T, Kawazoe S, Nakashita S, et al. Low-dose rectal diclofenac for prevention of post-endoscopic retrograde cholangiopancreatography pancreatitis: a randomized controlled trial. J Gastroenterol 2012;47:912-17.

90 Dumonceau JM, Andriulli A, Elmunzer BJ, et al. Prophylaxis of post-ERCP pancreatitis: European Society of Gastrointestinal Endoscopy (ESGE) Guidelineupdated June 2014. Endoscopy 2014;46:799-815.

91 Tarnasky PR, Palesch YY, Cunningham JT, et al. Pancreatic stenting prevents pancreatitis after biliary sphincterotomy in patients with sphincter of Oddi dysfunction. Gastroenterology 1998;115:1518-24.

92 Mazaki T, Mado K, Masuda H, et al. Prophylactic pancreatic stent placement and post-ERCP pancreatitis: an updated meta-analysis. J Gastroentero/ 2014;49: 343-55.

93 Afghani E, Akshintala VS, Khashab MA, et al. 5-Fr vs. 3-Fr pancreatic stents for the prevention of post-ERCP pancreatitis in high-risk patients: a systematic review and network meta-analysis. Endoscopy 2014;46:573-80.

94 Akbar A, Abu Dayyeh BK, Baron TH, et al. Rectal nonsteroidal anti-inflammatory drugs are superior to pancreatic duct stents in preventing pancreatitis after endoscopic retrograde cholangiopancreatography: a network meta-analysis. Clin Gastroenterol Hepatol 2013;11:778-83.

95 Veitch AM, Baglin TP, Gershlick AH, et al. Guidelines for the management of anticoagulant and antiplatelet therapy in patients undergoing endoscopic procedures. Gut 2008:57:1322-9.

96 Veitch AM, Vanbiervliet G, Gershlick AH, et al. Endoscopy in patients on antiplatelet or anticoagulant therapy, including direct oral anticoagulants: British Society of Gastroenterology (BSG) and European Society of Gastrointestinal Endoscopy (ESGE) guidelines. Gut 2016;65:374-89.

97 Baron TH, Kamath PS, McBane RD. New anticoagulant and antiplatelet agents: a primer for the gastroenterologist. Clin Gastroenterol Hepatol 2014;12:187-95.

98 Abraham NS, Castillo DL. Novel anticoagulants: bleeding risk and management strategies. Curr Opin Gastroenterol 2013;29:676-83.

99 Desai J, Granger CB, Weitz Jl, et al. Novel oral anticoagulants in gastroenterology practice. Gastrointest Endosc 2013;78:227-39.

100 Ersoz G, Tekesin 0, Ozutemiz AO, et al. Biliary sphincterotomy plus dilation with a large balloon for bile duct stones that are difficult to extract. Gastrointest Endosc 2003; $57: 156-9$

$101 \mathrm{Heo} \mathrm{JH}$, Kang DH, Jung HJ, et al. Endoscopic sphincterotomy plus large-balloon dilation versus endoscopic sphincterotomy for removal of bile-duct stones. Gastrointest Endosc 2007:66:720-6; quiz 768, 771.

$102 \mathrm{Kim} \mathrm{TH}, \mathrm{Kim} \mathrm{JH}$, Seo DW, et al. International consensus guidelines for endoscopic papillary large-balloon dilation. Gastrointest Endosc 2016;83:37-47.

103 Freeman ML, DiSario JA, Nelson DB, et al. Risk factors for post-ERCP pancreatitis: a prospective, multicenter study. Gastrointest Endosc 2001;54:425-34.

104 Freeman ML, Guda NM. Prevention of post-ERCP pancreatitis: a comprehensive review. Gastrointest Endosc 2004;59:845-64.

105 Testoni PA, Mariani A, Aabakken L, et al. Papillary cannulation and sphincterotomy techniques at ERCP: European Society of Gastrointestinal Endoscopy (ESGE) Clinical Guideline. Endoscopy 2016;48:657-83.

106 Liao WC, Tu YK, Wu MS, et al. Balloon dilation with adequate duration is safer than sphincterotomy for extracting bile duct stones: a systematic review and meta-analyses. Clin Gastroenterol Hepatol 2012;10:1101-9.

107 Liu Y, Su P, Lin S, et al. Endoscopic papillary balloon dilatation versus endoscopic sphincterotomy in the treatment for choledocholithiasis: a meta-analysis. J Gastroenterol Hepatol 2012;27:464-71.

108 Zhao HC, He L, Zhou DC, et al. Meta-analysis comparison of endoscopic papillary balloon dilatation and endoscopic sphincteropapillotomy. World J Gastroenterol 2013;19:3883-91.

109 Neuhaus H, Hoffmann W, Zillinger C, et al. Laser lithotripsy of difficult bile duct stones under direct visual control. Gut 1993:34:415-21.

110 Chen YK, Parsi MA, Binmoeller KF, et al. Single-operator cholangioscopy in patients requiring evaluation of bile duct disease or therapy of biliary stones (with videos). Gastrointest Endosc 2011;74:805-14
111 Maydeo A, Kwek BE, Bhandari S, et al. Single-operator cholangioscopy-guided laser lithotripsy in patients with difficult biliary and pancreatic ductal stones (with videos). Gastrointest Endosc 2011;74:1308-14.

112 Kalaitzakis $E$, Sturgess $R$, Kaltsidis $H$, et al. Diagnostic utility of single-user peroral cholangioscopy in sclerosing cholangitis. Scand J Gastroenterol 2014;49:1237-44.

113 Moon JH, Ko BM, Choi HJ, et al. Direct peroral cholangioscopy using an ultra-slim upper endoscope for the treatment of retained bile duct stones. $\mathrm{Am}$ J Gastroenterol 2009;104:2729-33.

114 Sethi A, Chen YK, Austin GL, et al. ERCP with cholangiopancreatoscopy may be associated with higher rates of complications than ERCP alone: a single-center experience. Gastrointest Endosc 2011;73:251-6.

115 Surgical Workload and Outcomes Audit Database (SWORD). http://www.augis.org/ sword/database (accessed 4/2015).

116 Moore MJ, Bennett CL. The learning curve for laparoscopic cholecystectomy. The Southern Surgeons Club. Am J Surg 1995;170:55-9.

117 Kenny R, Richardson J, McGlone ER, et al. Laparoscopic common bile duct exploration versus pre or post-operative ERCP for common bile duct stones in patients undergoing cholecystectomy: is there any difference? Int I Surg 2014;12:989-93.

118 Alexakis N, Connor S. Meta-analysis of one- vs. two-stage laparoscopic/endoscopic management of common bile duct stones. HPB (Oxford) 2012;14:254-9.

119 Rhodes M, Sussman L, Cohen L, et al. Randomised trial of laparoscopic exploration of common bile duct versus postoperative endoscopic retrograde cholangiography for common bile duct stones. Lancet 1998;351:159-61.

120 Cuschieri A, Lezoche E, Morino $M$, et al. E.A.E.S. multicenter prospective randomized trial comparing two-stage vs single-stage management of patients with gallstone disease and ductal calculi. Surg Endosc 1999;13:952-7.

121 Gurusamy K, Wilson E, Burroughs AK, et al. Intra-operative vs pre-operative endoscopic sphincterotomy in patients with gallbladder and common bile duct stones: cost-utility and value-of-information analysis. Appl Health Econ Health Policy 2012;10:15-29.

122 Tranter SE, Thompson MH. Comparison of endoscopic sphincterotomy and laparoscopic exploration of the common bile duct. Br J Surg 2002;89: 1495-504.

123 Zhang HW, Chen YJ, Wu CH, et al. Laparoscopic common bile duct exploration with primary closure for management of choledocholithiasis: a retrospective analysis and comparison with conventional T-tube drainage. Am Surg 2014;80:178-81.

124 Gurusamy KS, Koti R, Davidson BR. T-tube drainage versus primary closure after laparoscopic common bile duct exploration. Cochrane Database Syst Rev 2013;(6): CD005641.

125 Petelin JB. Laparoscopic common bile duct exploration. Surg Endosc 2003;17:1705-15.

126 DePaula AL, Hashiba K, Bafutto M. Laparoscopic management of choledocholithiasis. Surg Endosc 1994;8:1399-403.

127 Franklin ME Jr, Pharand D, Rosenthal D. Laparoscopic common bile duct exploration. Surg Laparosc Endosc 1994;4:119-24.

128 Berci G, Morgenstern L. Laparoscopic management of common bile duct stones. A multi-institutional SAGES study. Society of American Gastrointestinal Endoscopic Surgeons. Surg Endosc 1994;8:1168-74; discussion 1174-5.

129 Martin DJ, Vernon DR, Toouli J. Surgical versus endoscopic treatment of bile duct stones. Cochrane Database Syst Rev 2006;(2):CD003327.

130 Varban O, Assimos D, Passman C, et al. Video. Laparoscopic common bile duct exploration and holmium laser lithotripsy: a novel approach to the management of common bile duct stones. Surg Endosc 2010;24:1759-64.

131 Waage A, Strömberg C, Leijonmarck CE, et al. Long-term results from laparoscopic common bile duct exploration. Surg Endosc 2003;17:1181-5.

132 Riciardi R, Islam S, Canete JJ, et al. Effectiveness and long-term results of laparoscopic common bile duct exploration. Surg Endosc 2003;17:19-22.

133 Williams EJ, the Steering Committee, BSG Audit of ERCP. Diagnosis and management of suspected common bile duct stones in patients fit for cholecystectomy: a survey of 5 UK regions. Gut 2006;55:A94. (361) Abstract.

134 Ozcan N, Kahriman G, Mavili E. Percutaneous transhepatic removal of bile duct stones: results of 261 patients. Cardiovasc Intervent Radiol 2012;35:890-7.

135 Kint JF, van den Bergh JE, van Gelder RE, et al. Percutaneous treatment of common bile duct stones: results and complications in 110 consecutive patients. Dig Surg 2015;32:9-15.

136 Giovannini M, Moutardier V, Pesenti C, et al. Endoscopic ultrasound-guided bilioduodenal anastomosis: a new technique for biliary drainage. Endoscopy 2001:33:898-900.

137 Khan MA, Akbar A, Baron TH, et al. Endoscopic Ultrasound-Guided Biliary Drainage: A Systematic Review and Meta-Analysis. Dig Dis Sci 2016;61:684-703.

138 Maluenda F, Csendes A, Burdiles P, et al. Bacteriological study of choledochal bile in patients with common bile duct stones, with or without acute suppurative cholangitis. Hepatogastroenterology 1989;36:132-5.

139 Bergman JJ, Rauws EA, Tijssen JG, et al. Biliary endoprostheses in elderly patients with endoscopically irretrievable common bile duct stones: report on 117 patients. Gastrointest Endosc 1995;42:195-201. 
140 Chopra KB, Peters RA, O'Toole PA, et al. Randomised study of endoscopic biliary endoprosthesis versus duct clearance for bileduct stones in high-risk patients. Lancet 1996;348:791-3.

141 Di Giorgio P, Manes G, Grimaldi E, et al. Endoscopic plastic stenting for bile duct stones: stent changing on demand or every 3 months. A prospective comparison study. Endoscopy 2013;45:1014-17.

142 McAlister VC, Davenport E, Renouf E. Cholecystectomy deferral in patients with endoscopic sphincterotomy. Cochrane Database Syst Rev 2007;(4):CD006233.

143 Hammarström LE, Holmin T, Stridbeck H, et al. Long-term follow-up of a prospective randomized study of endoscopic versus surgical treatment of bile duct calculi in patients with gallbladder in situ. Br J Surg 1995;82:1516-21.

144 Targarona EM, Ayuso RM, Bordas JM, et al. Randomised trial of endoscopic sphincterotomy with gallbladder left in situ versus open surgery for common bileduct calculi in high-risk patients. Lancet 1996;347:926-9.

145 Suc B, Escat J, Cherqui D, et al. Surgery vs endoscopy as primary treatment in symptomatic patients with suspected common bile duct stones: a multicenter randomized trial. French Associations for Surgical Research. Arch Surg 1998;133:702-8.

146 Boerma D, Rauws EA, Keulemans YC, et al. Wait-and-see policy or laparoscopic cholecystectomy after endoscopic sphincterotomy for bile-duct stones: a randomised trial. Lancet 2002;360:761-5.

147 Lau JY, Leow CK, Fung TM, et al. Cholecystectomy or gallbladder in situ after endoscopic sphincterotomy and bile duct stone removal in Chinese patients. Gastroenterology 2006;130:96-103.

148 American Society of Anesthesiologists ASA Physical Classification System. https:/ www.asahq.org/resources/clinical-information/asa-physical-status-classificationsystem (accessed 23 Aug 2016)

149 Heo J, Jung MK, Cho CM. Should prophylactic cholecystectomy be performed in patients with concomitant gallstones after endoscopic sphincterotomy for bile duct stones? Surg Endosc 2015;29:1574-9.

150 Zargar SA, Mushtaq M, Beg MA, et al. Wait-and-see policy versus cholecystectomy after endoscopic sphincterotomy for bile-duct stones in high-risk patients with co-existing gallbladder stones: a prospective randomised trial. Arab J Gastroenterol 2014;15:24-6.

151 Tsai TJ, Lai KH, Lin CK, et al. The relationship between gallbladder status and recurrent biliary complications in patients with choledocholithiasis following endoscopic treatment. J Chin Med Assoc 2012;75:560-6.

152 Tsujino T, Kawabe T, Komatsu Y, et al. Endoscopic papillary balloon dilation for bile duct stone: immediate and long-term outcomes in 1000 patients. Clin Gastroenterol Hepatol 2007;5:130-7.

153 Ando T, Tsuyuguchi T, Okugawa $\mathrm{T}$, et al. Risk factors for recurrent bile duct stones after endoscopic papillotomy. Gut 2003;52:116-21.

154 Lee JK, Ryu JK, Park JK, et al. Risk factors of acute cholecystitis after endoscopic common bile duct stone removal. World J Gastroenterol 2006;12:956-60.

155 Cui ML, Cho JH, Kim TN. Long-term follow-up study of gallbladder in situ after endoscopic common duct stone removal in Korean patients. Surg Endosc 2013;27:1711-16

156 Kageoka M, Watanabe F, Maruyama Y, et al. Long-term prognosis of patients after endoscopic sphincterotomy for choledocholithiasis. Dig Endosc 2009;21:170-5.

157 Kwon SK, Lee BS, Kim NJ, et al. Is cholecystectomy necessary after ERCP for bile duct stones in patients with gallbladder in situ? Korean J Intern Med 2001;16:254-9.

158 Costamagna G, Tringali A, Shah SK, et al. Long-term follow-up of patients after endoscopic sphincterotomy for choledocholithiasis, and risk factors for recurrence. Endoscopy 2002;34:273-9.

159 Adamek HE, Kudis V, Jakobs R, et al. Impact of gallbladder status on the outcome in patients with retained bile duct stones treated with extracorporeal shockwave lithotripsy. Endoscopy 2002;34:624-7.

160 Hammarstrom LE, Holmin T, Stridbeck H. Endoscopic treatment of bile duct calculi in patients with gallbladder in situ: long-term outcome and factors. Scand J Gastroenterol 1996;31:294-301.

161 Freeman ML, Nelson DB, Sherman S, et al. Complications of endoscopic biliary sphincterotomy. N Engl J Med 1996;335:909-18.

162 Masci E, Toti G, Mariani A, et al. Complications of diagnostic and therapeutic ERCP: a prospective multicenter study. Am J Gastroenterol 2001;96:417-23.

163 Mitchell RM, O'Connor F, Dickey W. Endoscopic retrograde cholangiopancreatography is safe and effective in patients 90 years of age and older. J Clin Gastroenterol 2003;36:72-4.

164 García-Cano Lizcano J, González Martin JA, Taberna Arana L, et al. [Therapeutic biliary endoscopy in patients over 90 years of age]. An Med Interna 2002;19:409-11.

165 Lygidakis NJ. Operative risk factors of cholecystectomy-choledochotomy in the elderly. Surg Gynecol Obstet 1983;157:15-19.
166 Siegel JH, Kasmin FE. Biliary tract diseases in the elderly: management and outcomes. Gut 1997;41:433-5.

167 González JJ, Sanz L, Grana JL, et al. Biliary lithiasis in the elderly patient: morbidity and mortality due to biliary surgery. Hepatogastroenterology 1997;44:1565-8.

168 Hacker KA, Schultz CC, Helling TS. Choledochotomy for calculous disease in the elderly. Am J Surg 1990;160:610-12; discussion 613.

169 Lai EC, Mok FP, Tan ES, et al. Endoscopic biliary drainage for severe acute cholangitis. N Engl J Med 1992:326:1582-6.

170 Hou LA, Laine L, Motamedi N, et al. Optimal timing of endoscopic retrograde cholangiopancreatography in acute cholangitis. J Clin Gastroenterol 2016. Published Online First: Nov 212016

171 Barnard J, Siriwardena AK. Variations in implementation of current national guidelines for the treatment of acute pancreatitis: implications for acute surgical service provision. Ann R Coll Surg Engl 2002;84:79-81.

172 Mofidi R, Madhavan KK, Garden OJ, et al. An audit of the management of patients with acute pancreatitis against national standards of practice. $\mathrm{Br} J$ Surg 2007;94:844-8.

173 Tse F, Yuan Y. Early routine endoscopic retrograde cholangiopancreatography strategy versus early conservative management strategy in acute gallstone pancreatitis. Cochrane Database Syst Rev 2012;(5):CD009779.

174 Alimoglu 0, Ozkan OV, Sahin M, et al. Timing of cholecystectomy for acute biliary pancreatitis: outcomes of cholecystectomy on first admission and after recurrent biliary pancreatitis. World J Surg 2003;27:256-9.

175 Hernandez V, Pascual I, Almela P, et al. Recurrence of acute gallstone pancreatitis and relationship with cholecystectomy or endoscopic sphincterotomy. Am J Gastroenterol 2004;99:2417-23.

176 van Baal MC, Besselink MG, Bakker OJ, et al. Timing of cholecystectomy after mild biliary pancreatitis: a systematic review. Ann Surg 2012;255:860-6.

177 da Costa DW, Bouwense SA, Schepers NJ, et al. Same-admission versus interval cholecystectomy for mild gallstone pancreatitis (PONCHO): a multicentre randomised controlled trial. Lancet 2015;386:1261-8.

178 da Costa DW, Schepers NJ, Römkens TE, et al. Endoscopic sphincterotomy and cholecystectomy in acute biliary pancreatitis. Surgeon 2016;14:99-108.

179 Mustafa A, Begaj I, Deakin M, et al. Long-term effectiveness of cholecystectomy and endoscopic sphincterotomy in the management of gallstone pancreatitis. Surg Endosc 2014;28:127-33.

180 Enestvedt BK, Kothari S, Pannala R, et al. Devices and techniques for ERCP in the surgically altered GI tract. Gastrointest Endosc 2016;83:1061-75.

181 Gómez V, Petersen BT. Endoscopic Retrograde Cholangiopancreatography in Surgically Altered Anatomy. Gastrointest Endosc Clin N Am 2015;25:631-56.

$182 \mathrm{Kim} \mathrm{MH}$, Lee SK, Lee MH, et al. Endoscopic retrograde cholangiopancreatography and needle-knife sphincterotomy in patients with Billroth II gastrectomy: a comparative study of the forward-viewing endoscope and the side-viewing duodenoscope. Endoscopy 1997:29:82-5.

183 Çiçek B, Parlak E, Disibeyaz S, et al. Endoscopic retrograde cholangiopancreatography in patients with Billroth II gastroenterostomy. J Gastroenterol Hepatol 2007;22:1210-13.

184 Bove V, Tringali A, Familiari $P$, et al. ERCP in patients with prior Billroth I gastrectomy: report of 30 years' experience. Endoscopy 2015;47:611-16.

185 Bergman JJ, van Berkel AM, Bruno MJ, et al. A randomized trial of endoscopic balloon dilation and endoscopic sphincterotomy for removal of bile duct stones in patients with a prior Billroth II gastrectomy. Gastrointest Endosc 2001:53:19-26.

186 Kim TN, Lee SH. Endoscopic Papillary Large Balloon Dilation Combined with Guidewire-Assisted Precut Papillotomy for the Treatment of Choledocholithiasis in Patients with Billroth II Gastrectomy. Gut Liver 2011;5:200-3.

187 Shah RJ, Smolkin M, Yen R, et al. A multicenter, U.S. experience of single-balloon, double-balloon, and rotational overtube-assisted enteroscopy ERCP in patients with surgically altered pancreaticobiliary anatomy (with video). Gastrointest Endosc 2013;77:593-600.

188 Attam R, Leslie D, Freeman M, et al. EUS-assisted, fluoroscopically guided gastrostomy tube placement in patients with Roux-en-Y gastric bypass: a nove technique for access to the gastric remnant. Gastrointest Endosc 2011;74:677-82.

189 Baron TH, Song LM. Percutaneous assisted transprosthetic endoscopic therapy (PATENT): expanding gut access to infinity and beyond! (with video). Gastrointest Endosc 2012;76:641-4.

190 Tyberg A, Nieto J, Salgado S, et al. Endoscopic ultrasound (EUS)-directed transgastric endoscopic retrograde cholangiopancreatography or EUS: mid-term analysis of an emerging procedure. Clin Endosc 2016. Published Online First: Sep 192016

191 Schreiner MA, Chang L, Gluck M, et al. Laparoscopy-assisted versus balloon enteroscopy-assisted ERCP in bariatric post-Roux-en- $Y$ gastric bypass patients. Gastrointest Endosc 2012;75:748-56. 